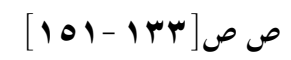

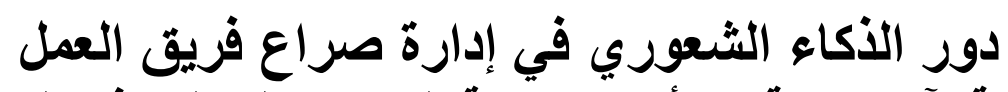

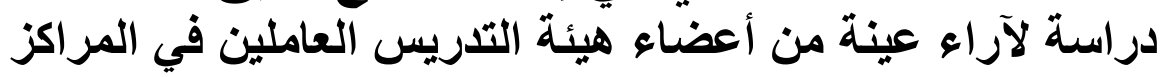

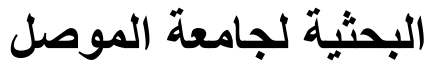

\author{
ريم سعد الجميل \\ مدرس مساعد - قسم إدارة الأعمال \\ كلية الإدارة والاقتصاد -جامعة الموصل
}

\begin{abstract}
المستخلص
يرتبط الذكاء الشعوري بإدارة الشعور وإمكانية الفرد في السيطرة على، والتحكم باتفعالاته التهله

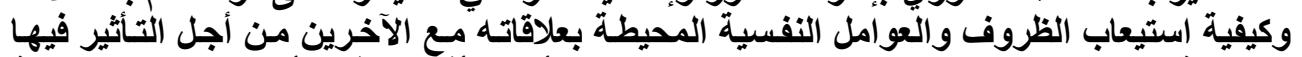

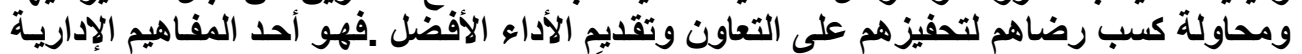

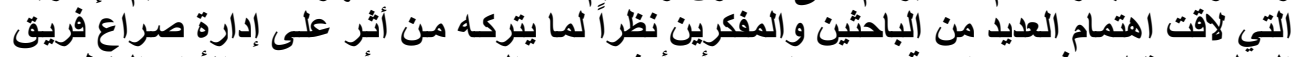

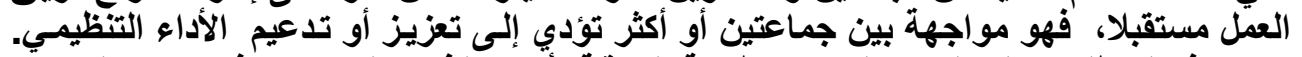

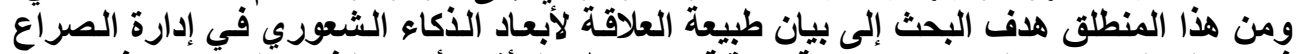

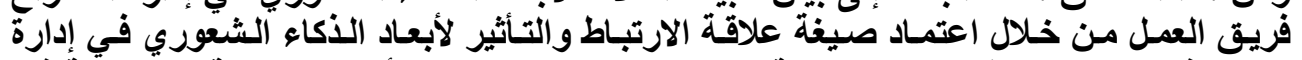

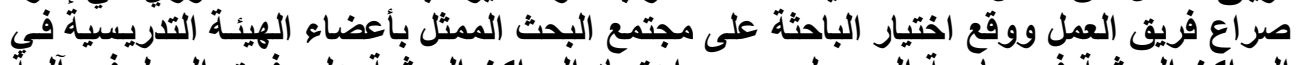

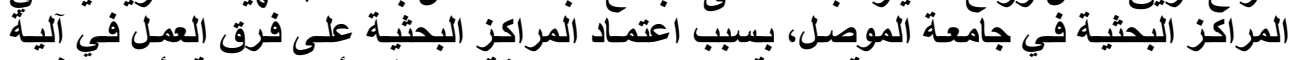

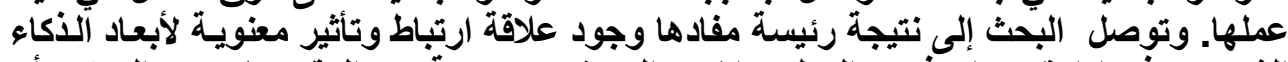

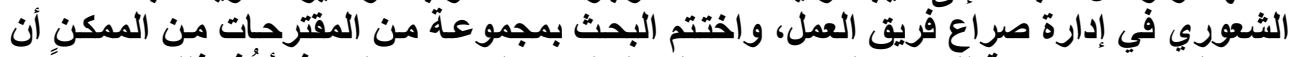

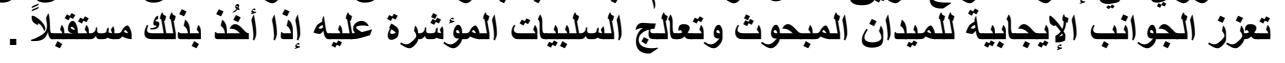

$$
\text { الكلمات المفتاحية: الذكاء الثعوري، صراع فريق العمل، اسليب معالجة. }
$$




\title{
The Role of Emotional Intelligence in Managing Work Teams Conflict A Study For Opinions of Sample of Lecturer Members in Research Centers in Mosul University
}

\author{
Reem Saad Al Jameel \\ Assistant Lecturer \\ Department of Business Administration \\ University of Mosul
}

\begin{abstract}
The emotional intelligence is however linked with managing emotions and the capabilities of the individual to control and govern his emotions. The ability to treat circumstances and psychological factors surrounded his/her relationships with others, in order to have an effect on them. The target to gain the satisfaction of others is to consent the cooperation and present the best implementation. It is regarded as one of the administrative concepts that have received attention of many researchers and thinkers because it has a positive impact in managing the conflict among work teams in the future. The facing of two or more groups leads to the reinforcement or the support of organizational implementation. On this concept, the research aimed to explain the nature of the relationship of keeping aside or the exclusion of the emotional intelligence in managing the conflict among work teams through the adoption of a method to find the correlation and effect of keeping aside or the exclusion of the emotional intelligence in managing the conflict among work teams. The researcher has chosen the society of members of the teaching faculty at the research centers at the University of Mosul, because concepts that have received attention of many researchers and thinkers because it has a positive impact in managing the conflict among work teams in the future. The facing of two or more groups leads to the reinforcement or the support of organizational implementation. On this basis, the research aimed to explain the nature of the relationship of keeping aside or the exclusion of the emotional intelligence in managing the conflict among work teams.
\end{abstract}

\section{Key Words:}

Emotional Intelligence, Work Teams Conflict , Treatment Methods.

المقدمة

يعـد الـكاء الشُعوري مفهومـاً معاصـراً يمساز ج بـين متغيـرين أساسـين همـا الذكاء

و الثعور أو العاطفة، حيث يشير إلى سبل توظيف الذكاء في السيطرة على الثعور لاتخـاذ

قرار ات إدارية و إنسانية صائبة. والذكاء الثعوري هو مجمو عة من القابليات غير الإدر اكيـة

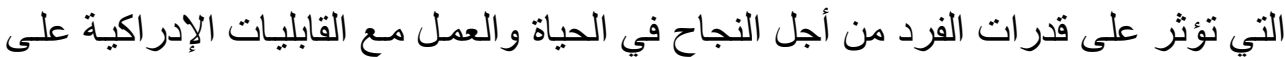

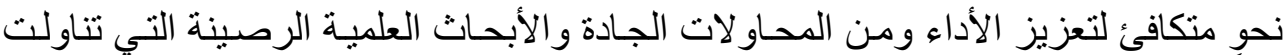

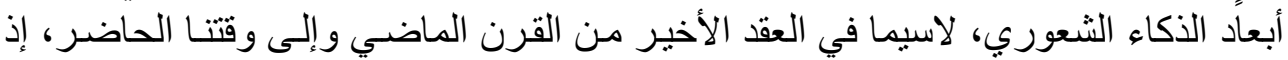

تبرز في مقدمتها در اسـة العـالم GOLEMAN في جامعة هارفارد الذي حدد أبعـاد الذكاء

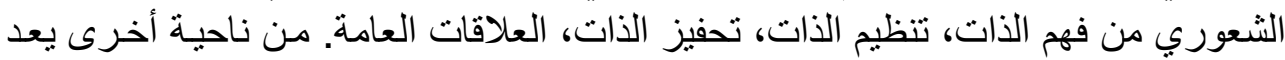

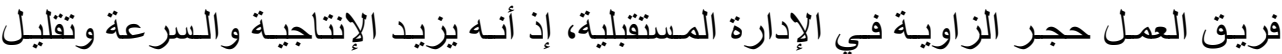

التكاليف ويحسن الجودة والحد من التتافس الداخلي المدمر وتحسين تماسكية موقع العمل. 
فالصر اع هو الميزة المستديمة في أي موقع عمل، وهو العملية التي يلاحظ من خلالها

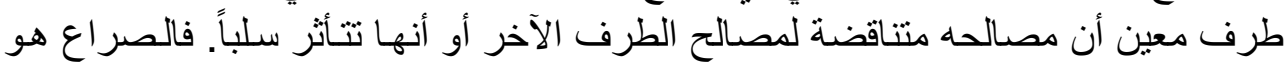

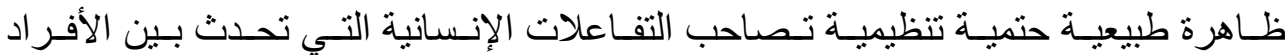

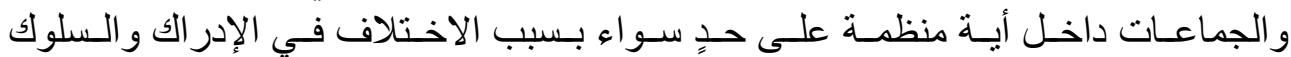
و الظروف المو اجهة والثقافة، وينبغي إدارتها وتحقيق أقصى فائدة ممكنة منها . عليه سيتناول بحثنا الحالي المحاور الآتية: المحور الأول: منهجية البحث. الدحور الثاني: الذكاء الثُعوري، إدارة الئه صراع فريق العمل (إطار مفاهيمي). المحور الثالث: الإطار الميداني للبحث.

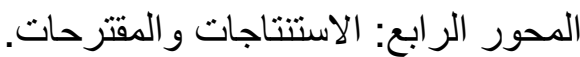

بناءً على مـا تقدم في مقدمة البحث يمكن التعبير عن مشكلته بعدد من التساؤلات

منهجية البحث مشكلة البحث البحث

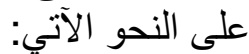
1. هل بمتلك عناصر فريق العمل في المر اكز البحثية في جامعة الموصل تصور عن عن دور

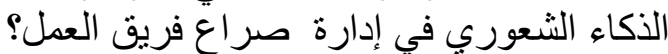

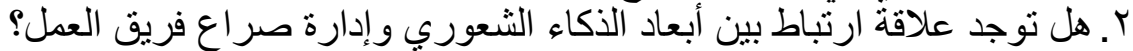

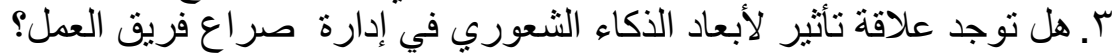

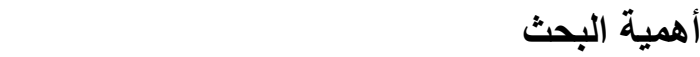

تتجسد أهمية البحث في جانبين مهمين هما:

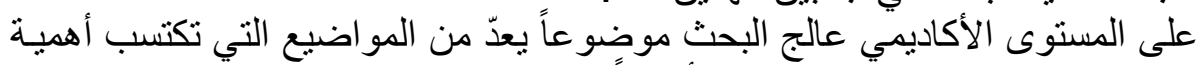

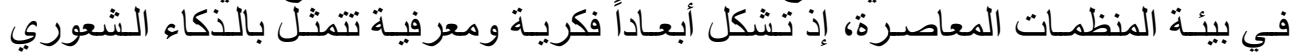

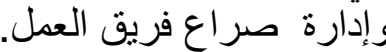

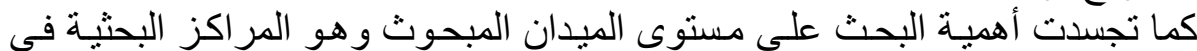

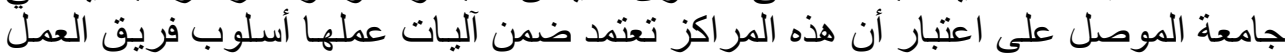

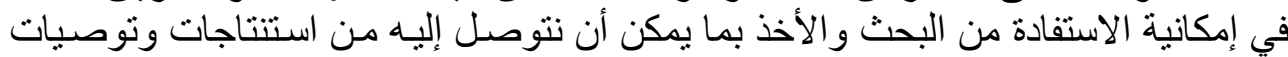
بهذف تحسين الأداء و الفاعلية بصورة الفية والفضل.

بهدف البحث في إطاره العام إلى توفير إطار أكاديمي علمي للذكاء الشعوري ودئ ودوره أهداف البحث

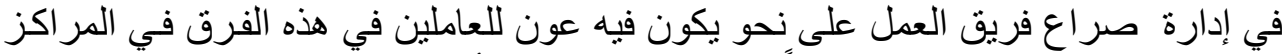

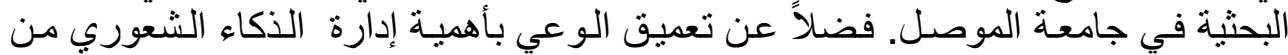

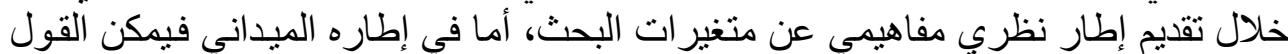

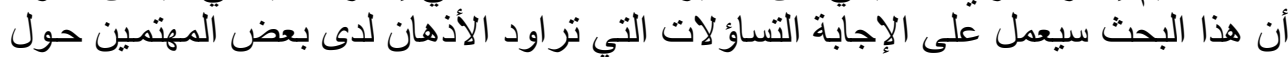

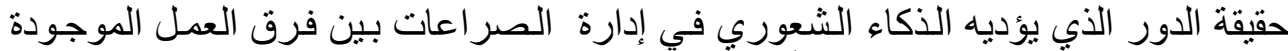

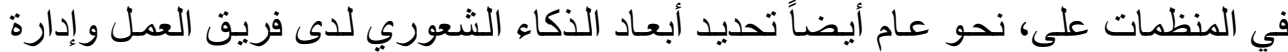




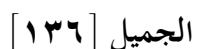

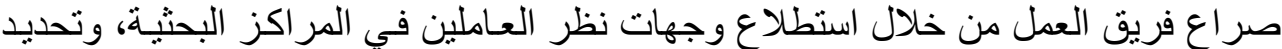
طبيعة العلاقة الارتباطية والتأثيرية بين أبعاد الذكاء الثشعوري و إدارة صر اعلئ فريق العمل.

فرضيات البحث

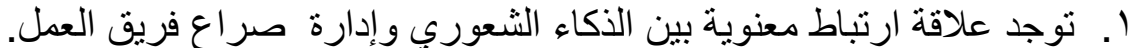

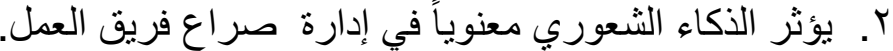

بعتمد البحث على المنهج الوصفي التحليلي في دراسته للعلاقة بين الذكاء الشعوري

تقتيات البحث

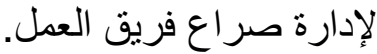

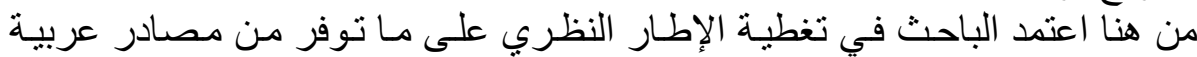

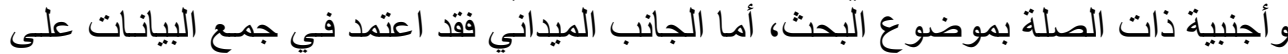

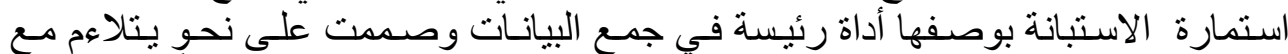

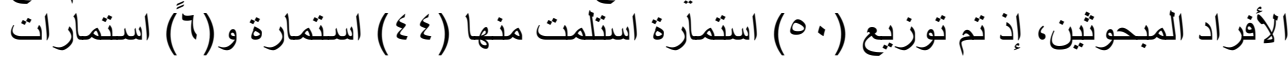

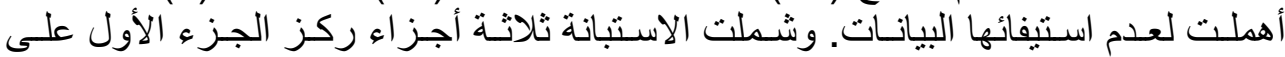

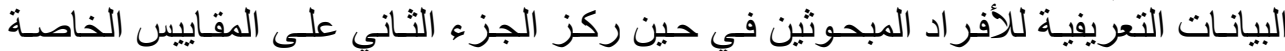

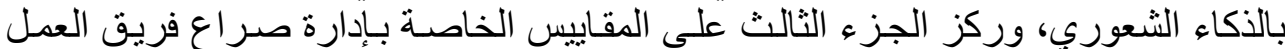

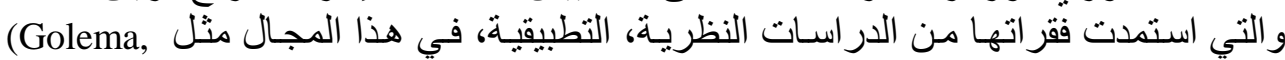

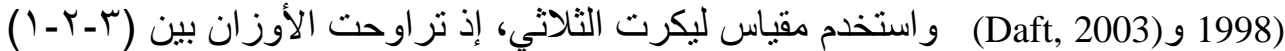

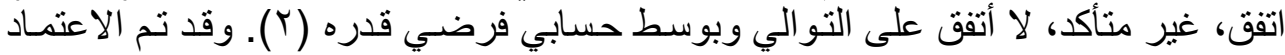

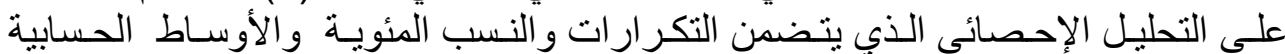

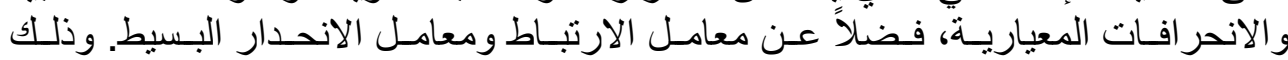

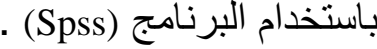

\section{وصف خصائص عينة البحث}

يبين الجدول التوزيع أفر اد العينة بحسب أسس متعددة: الجنس، العمر ، التحصيل

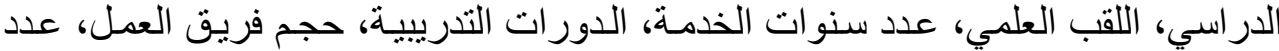

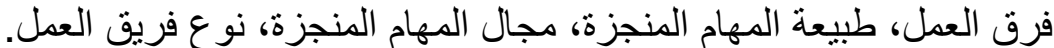

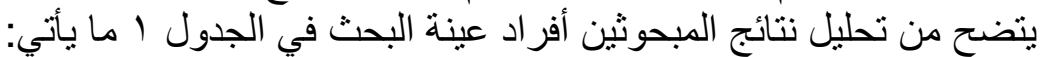

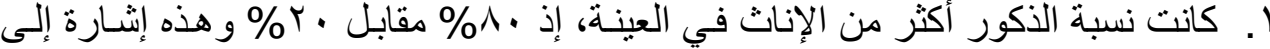

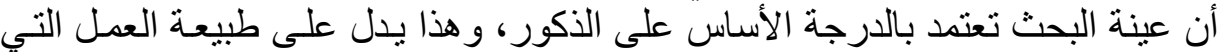

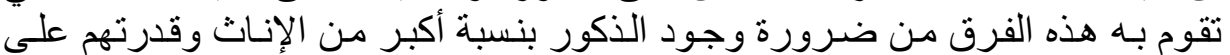

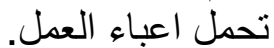

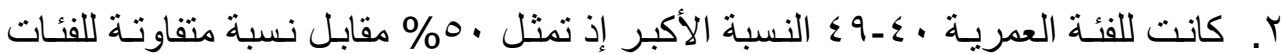

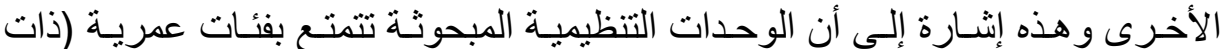

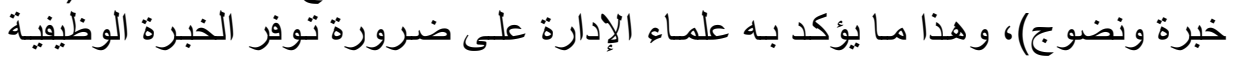

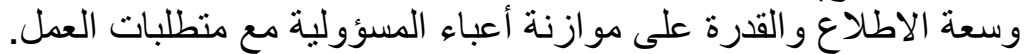

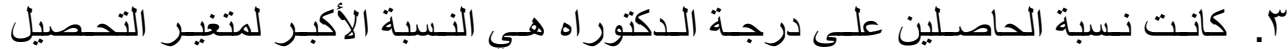

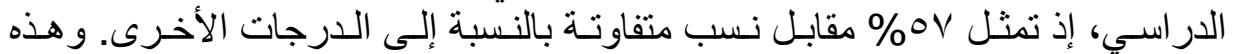


إنشارة إلى أن الوحدات التنظيمية المبحوثة في جامعـة الموصل تتمتع بمؤهلات علمية

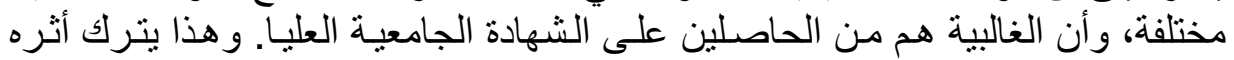

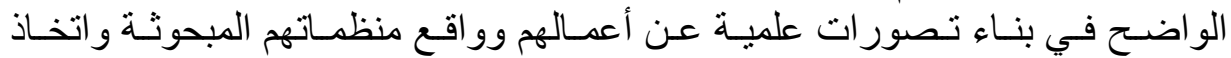

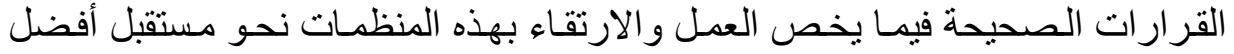
وتحقيق أهدافها في البقاء والنمو. في النها

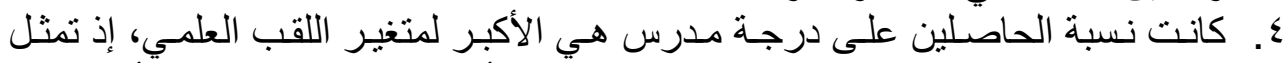

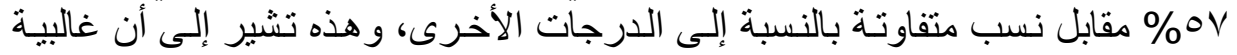

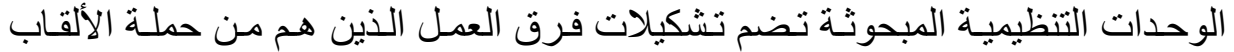
العلمية وهي ناحية إيجابية.

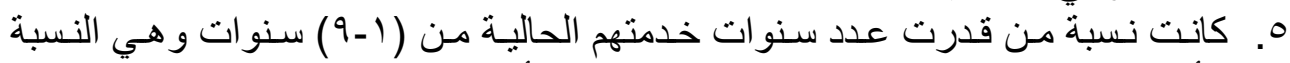

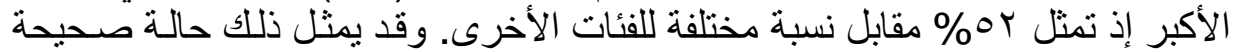

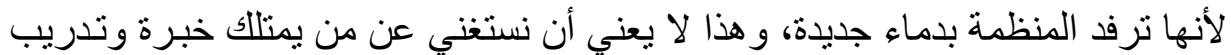

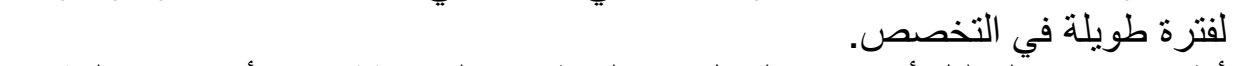

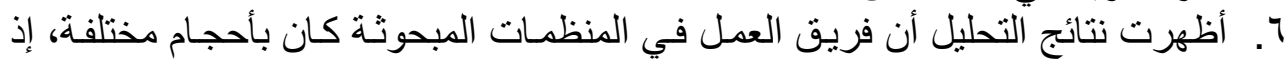

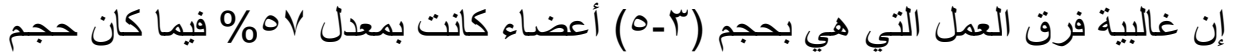

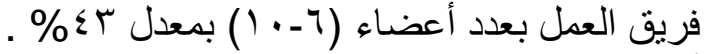

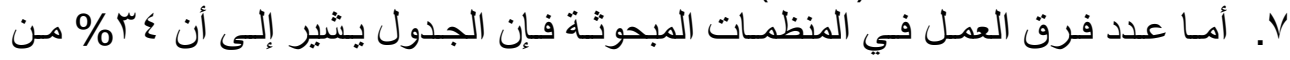

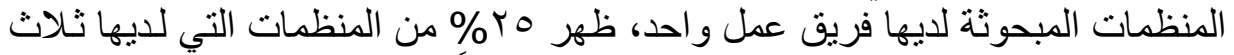

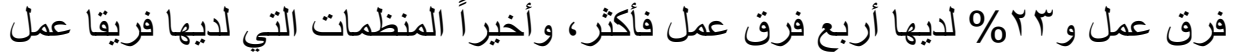

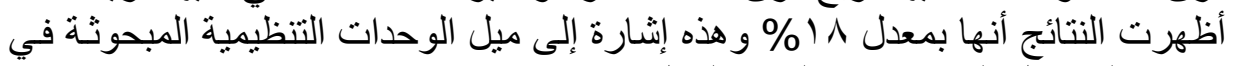

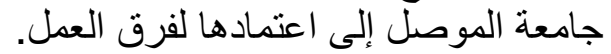

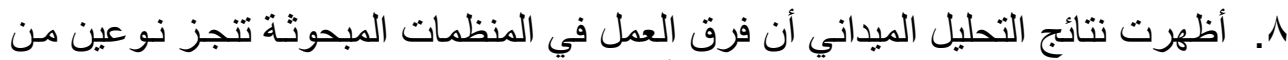

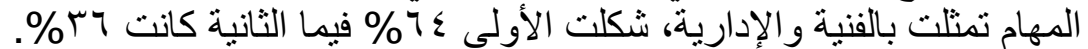

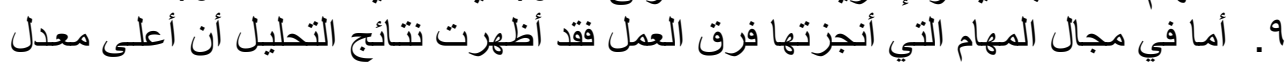

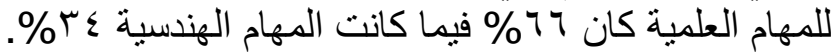

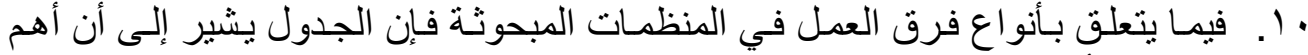

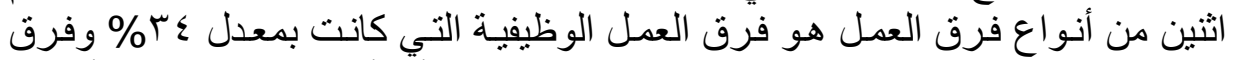

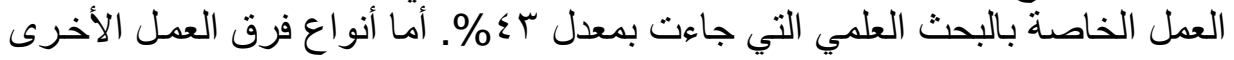

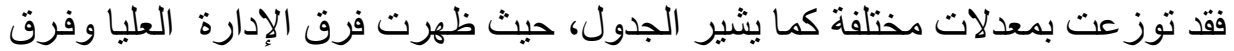

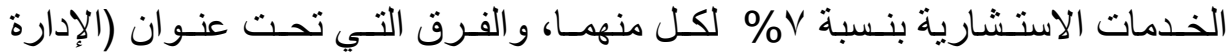

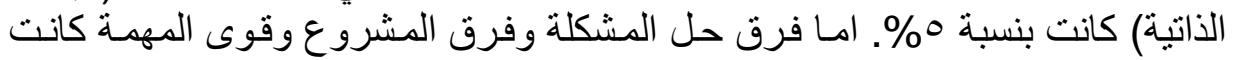

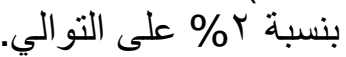

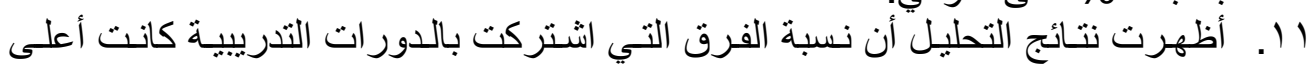

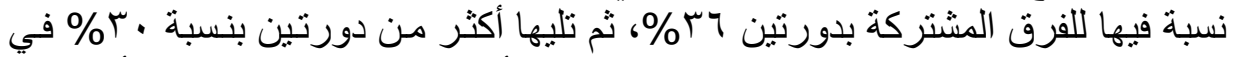

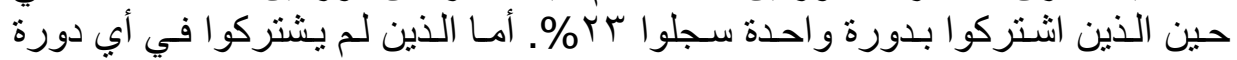

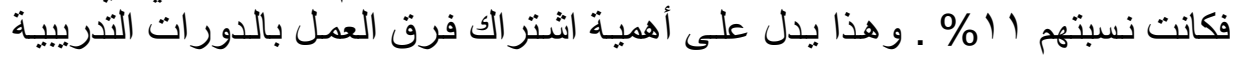
التي تعزز المهار ات والإبداع لأى فريق العمل. 
الجميل [مبا]

الجدول إنجول

توزيع الأفراد المبحوثين في المنظمات عينة البحث

\begin{tabular}{|c|c|c|c|}
\hline النسبةة & العدد & الفئات والمسميات & المتغير \\
\hline$\% \wedge$. & ro & ذكر & الجنس \\
\hline$\%$ \%. & 9 & أنثى & \\
\hline$\% 1 \ldots$ & $\varepsilon \varepsilon$ & \multicolumn{2}{|c|}{ المجموع } \\
\hline$\% 0$ & $r$ & rq-Yo & \multirow[t]{4}{*}{ العمر } \\
\hline$\%$ TV & ir & rq-r. & \\
\hline$\% \circ$. & rr & $\leqslant 9-\varepsilon$. & \\
\hline$\% \backslash 1$ & $\Lambda$ & • & \\
\hline$\% 1 \ldots$ & $\Sigma \varepsilon$ & \multicolumn{2}{|c|}{ المجموع } \\
\hline$\% \circ \mathrm{V}$ & ro & دكتور اه & \multirow[t]{4}{*}{ التحصيل الدراسي } \\
\hline$\% \varepsilon r$ & 19 & ماجستير & \\
\hline- & - & دبلوم عالٍ & \\
\hline- & - & بكالوريوس & \\
\hline$\% 1 \ldots$ & $\varepsilon \varepsilon$ & \multicolumn{2}{|c|}{ المجموع } \\
\hline- & - & أستاذ أ & \multirow{4}{*}{ اللقب العلمي } \\
\hline$\% r$. & 9 & أستاذ مساعد & \\
\hline$\% \circ \mathrm{V}$ & ro & مدرس & \\
\hline \%rr & $1 \cdot$ & مدرس مساعد & \\
\hline$\% 1 \ldots$ & $\leq \varepsilon$ & \multicolumn{2}{|c|}{ المجموع } \\
\hline$\% \circ r$ & $r \mu$ & $9-1$ & \multirow[t]{4}{*}{ سنوات الخدمة } \\
\hline$\% 11$ & 0 & $19-1$. & \\
\hline$\%$ \%r & $1 \cdot$ & rq-r. & \\
\hline$\% 1 \leq$ & 7 & • ب فما فوق & \\
\hline$\% 1 \ldots$ & $\varepsilon \varepsilon$ & \multicolumn{2}{|c|}{ المجموع } \\
\hline$\% 11$ & 0 & لم بشترك في أي دورة & \multirow[t]{4}{*}{ الدورات التدريبية } \\
\hline$\%$ \%r & $1 \cdot$ & دورة واحدة & \\
\hline$\%$ \% & 17 & دورتين & \\
\hline$\%$ \%. & 14 & أكثر من دورتين & \\
\hline$\% 1 \ldots$ & $\varepsilon \varepsilon$ & \multicolumn{2}{|c|}{ المجموع } \\
\hline$\%$ oV & ro & $0-4$ & \multirow[t]{3}{*}{ حجم فريق العمل } \\
\hline$\% \leq r$ & 19 & $1 \cdot-7$ & \\
\hline- & - & ا 11 أكثر & \\
\hline$\% 1 \ldots$ & $\varepsilon \varepsilon$ & \multicolumn{2}{|c|}{ المجموع } \\
\hline$\% \Gamma \varepsilon$ & 10 & فريق عمل واحد & \multirow{4}{*}{ مستوى الوحدة التنظيمية عدلى } \\
\hline$\% 11$ & $\Lambda$ & فريقا عمل & \\
\hline$\%$ ro & 11 & ثلاثة فرق عمل & \\
\hline$\%$ \%r & 1. & أربعة فرق عمل فأكثر & \\
\hline$\% 1 \ldots$ & $\varepsilon \varepsilon$ & \multicolumn{2}{|c|}{ المجموع } \\
\hline$\% 7 \varepsilon$ & rA & فنية & \multirow{2}{*}{ طبيعة المهام المنجزة لفرق } \\
\hline$\%$ & 17 & إدارية & \\
\hline$\% 1 \ldots$ & $\varepsilon \leqslant$ & \multicolumn{2}{|c|}{ المجموع } \\
\hline$\%$ \% & 10 & هندسية & مجال المهام المنجزة من \\
\hline
\end{tabular}




\begin{tabular}{|c|c|c|c|}
\hline النسبة & العدد & الفئات و المسميات & المتغير \\
\hline- & - & زر اعية & \multirow[t]{5}{*}{ قبل فريق العمل } \\
\hline - & - & قانونية & \\
\hline- & - & قانونية & \\
\hline$\% 77$ & rq & علمية & \\
\hline- & - & أخرى & \\
\hline$\% 1 \ldots$ & $\varepsilon \varepsilon$ & \multicolumn{2}{|c|}{ المجموع } \\
\hline$\%$ \% & 10 & وظيفي & \multirow[t]{9}{*}{ نوع فريق العمل } \\
\hline$\% V$ & $r$ & الإدارة العليا & \\
\hline$\% r$ & 1 & المستوى وقوى المهمة & \\
\hline$\% V$ & $r$ & الخدمات الاستشارية & \\
\hline- & - & الوظائف المنشابكة & \\
\hline$\% r$ & 1 & حل المشكلة & \\
\hline$\% \circ$ & $r$ & الإدارة الذاتية & \\
\hline$\% \leq r$ & 19 & البحث العلمي & \\
\hline- & - & أخرى تذكر & \\
\hline$\% 1 \ldots$ & $\varepsilon \varepsilon$ & \multicolumn{2}{|c|}{ المجموع } \\
\hline
\end{tabular}

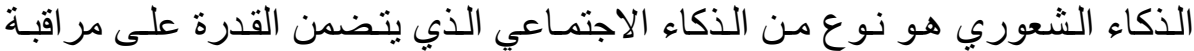

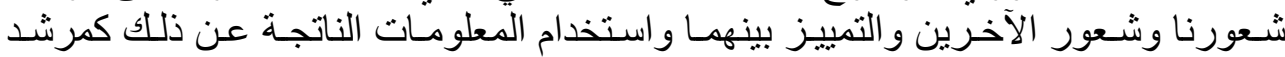

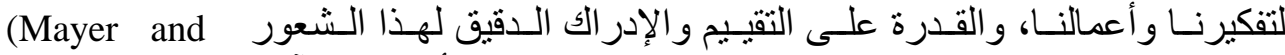
Higgs and وهو القدرة على تنظيم الشعور و التأثنير في الآخرين (Salovey,1999,10)

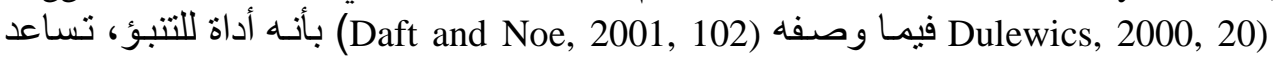

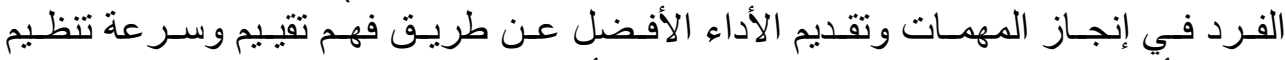

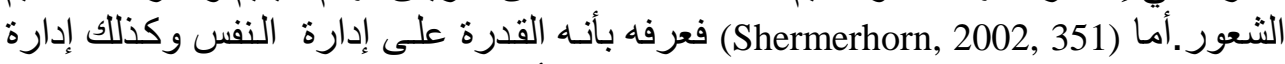

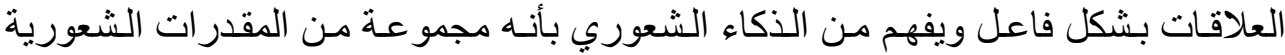

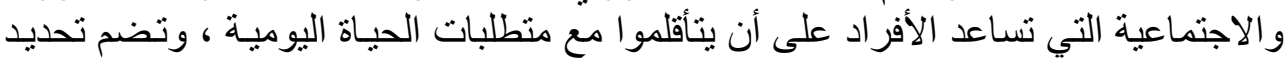

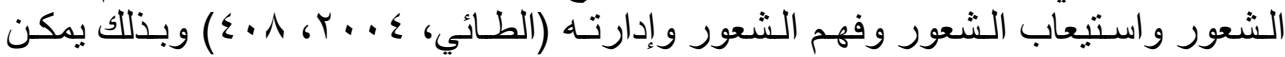

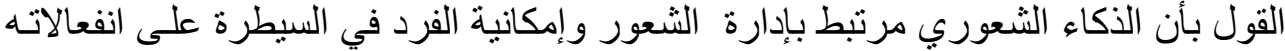

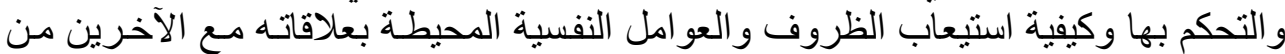

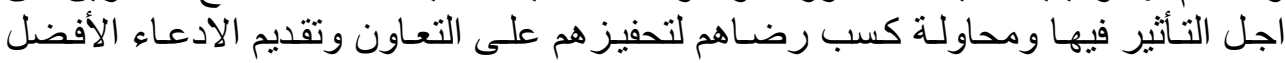

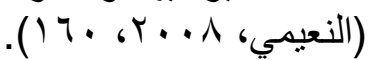

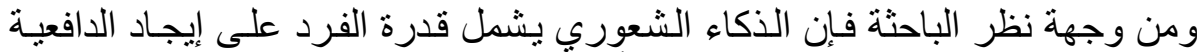
لديه و على الإصر ار و الثبات عندما يكون محبطاً وكذلك السيطرة على النفس لضبط الشعاء الشعور

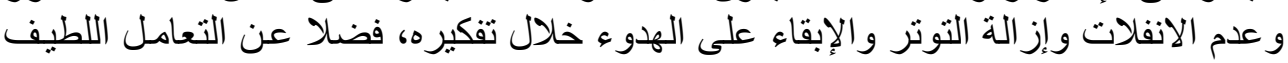

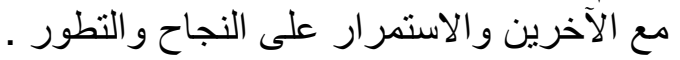


ثانياً أبعاد الذكاء الثعوري

هناك العديد من الدراسات و الأبحاث العلمية التي تناولت أبعاد الذكاء الشعوري وفي الثياء

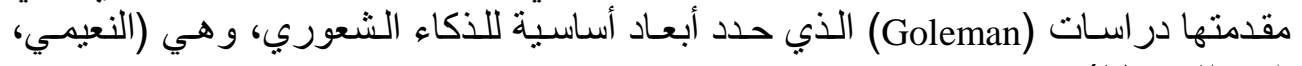

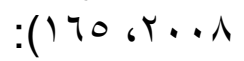

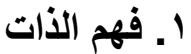

و وهو قدرة الفرد على فهم إمكاناته بأن يعي شعور الآخرين و أمزجتهم، وبذلك يساعده.

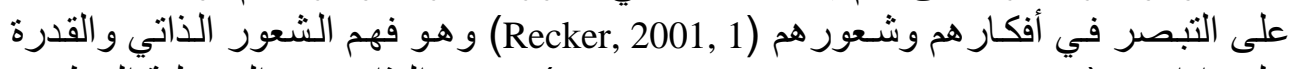

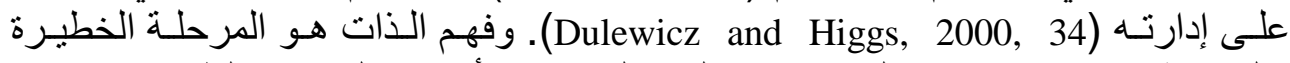

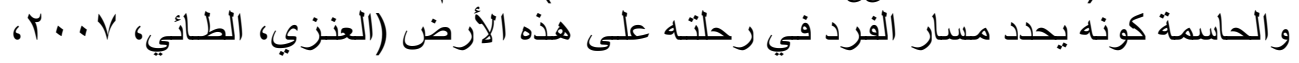
. 74 و هو القابلية على معرفة المشاعر الذاتية وفهمها، قابلية التمييز بين المشاعر والقدرة

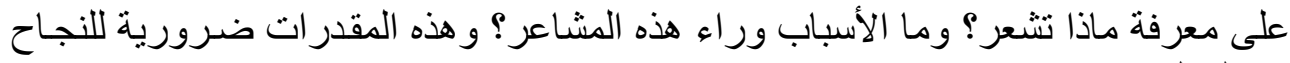
في العمل (Rothe man, 2002, 24-25).

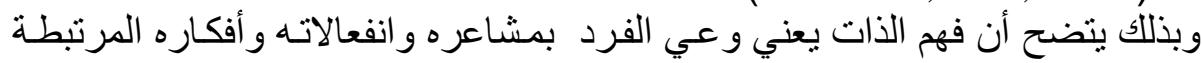

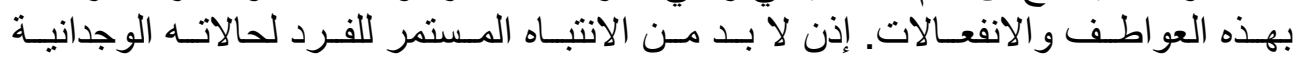
و الانفعالية من خلال ملاحظة الفعل ووجود الخبرة بما في تلألك العاطفة.

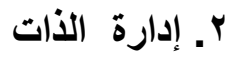

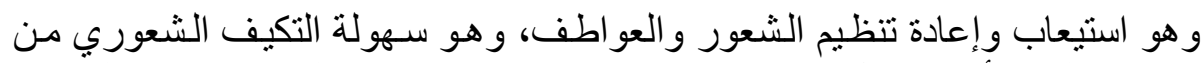

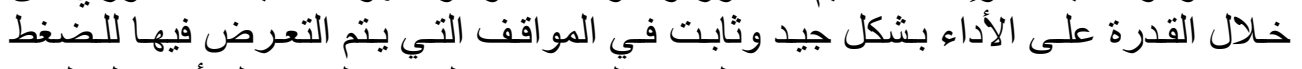
ـ ـ القدرة على إصدار الحكم و التفكير المتأني فبل القيام (Dulewicz and Higgs, 2000, 34)

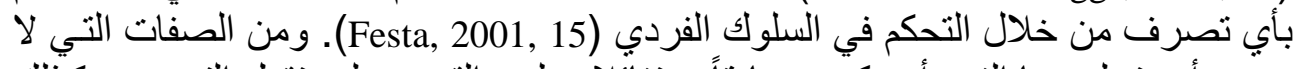

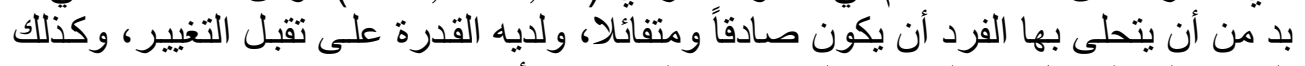

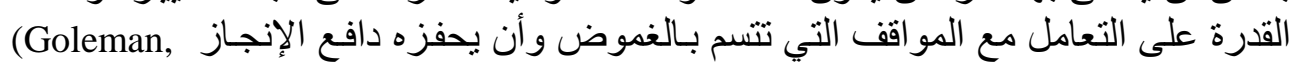
.1998, 82)

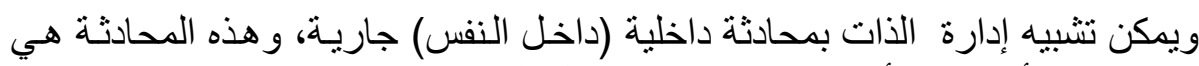

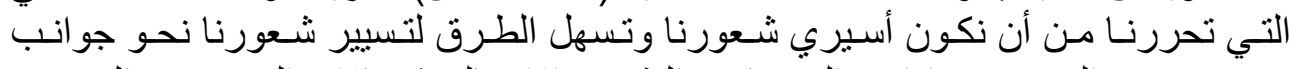

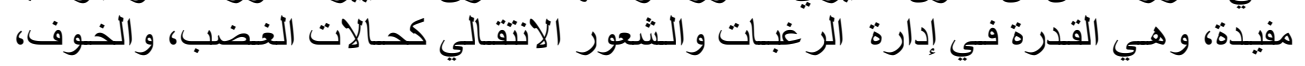

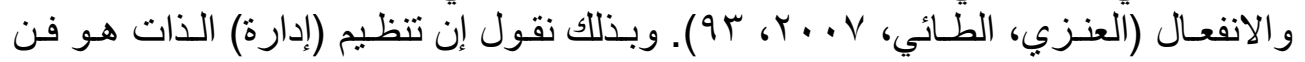

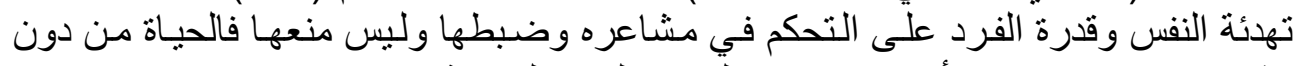

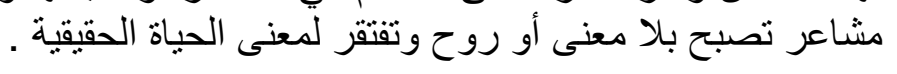

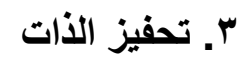

تحفيز الذات (الدافعية الذاتية) هي استكشاف المواهب الذاتية التي يتميز بها الأفراد

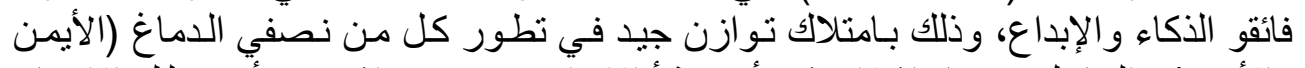

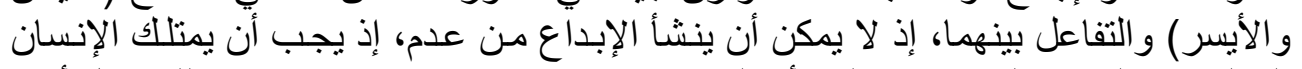

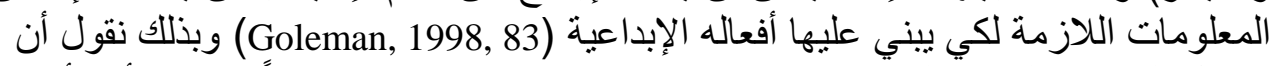

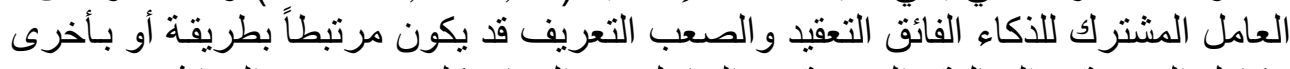
بتكامل السرعة، والفعالية والمرونة في التفاعل بين المهام بكل من نصفي الدماغ. 


\section{ك. - الفهم الاجتماعي (العاطفة)}

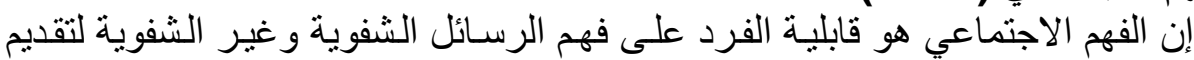

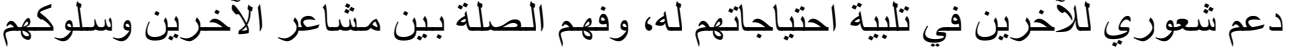
(Goleman, 1998, 94) ويتضمن الفهم الاجتماعي التعامل بحساسية مع الثقافات و البيئات الأخرى، وتقديم خدمة متميزة للزبائن، و الكفاءة في تطوير الأفراد و الاستفادة منهم (Goleman, 1998, 103).

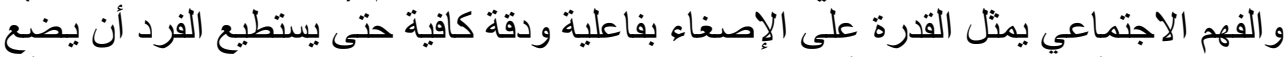

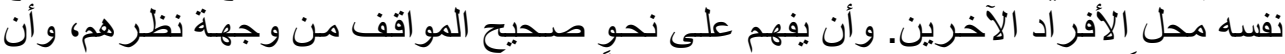
يكون قادراً على فهم حاجاتهم ور غباتهم، ومعرفةً اتخاذ القرار الارات عليهم (العنزي، الطائي،

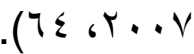
وبذلك يتضح لنا بأن الفهم الاجتماعي (العاطفة) هي مهارات التواصل التهل مع الآخرين اذ إن القدرة على إدارة العو اطف والمشاعر مع الآخرين هي أسـاس تناول العلاقاتات على الآى نحوٍ صحي وسليم.

هـ إدارة العلاقات (المقدرات الاجتماعية)

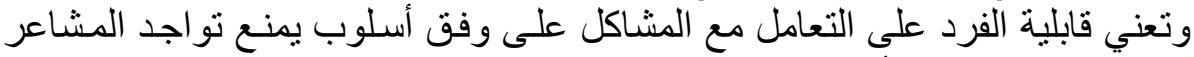

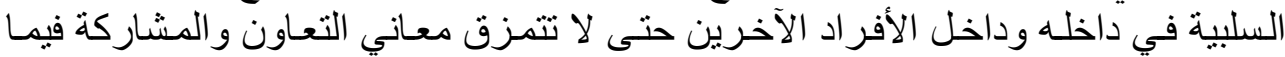

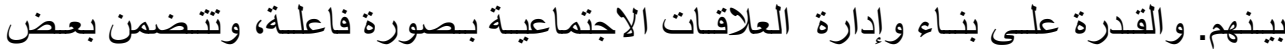

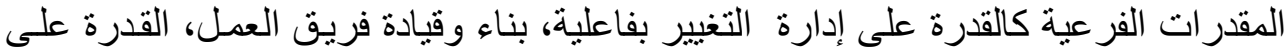
الإقتاع، والتأثير و إدارة الصراع (Goleman, 1998, 193). فالمقدرات العلاقاتية تتمثل بالإدر الك الاجتماعي و العلاقة بين الأفر اد، أبي القدرة على الإنى

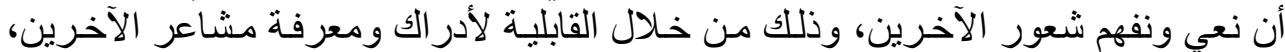

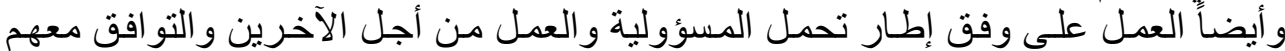

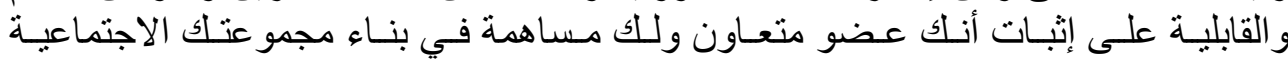

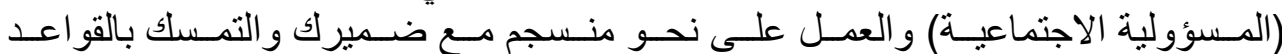

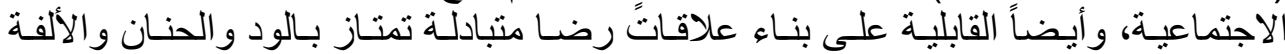

و والمحافظة عليها عن طريق العلاقة بين الأفر اد (Goleman, 1998,193).

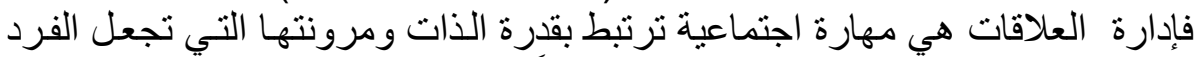

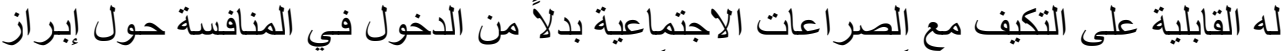

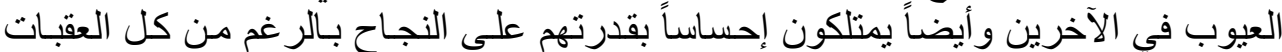

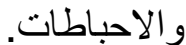

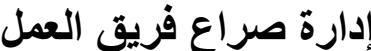
أولاً - مفهوم صراع فراع فريق العمل

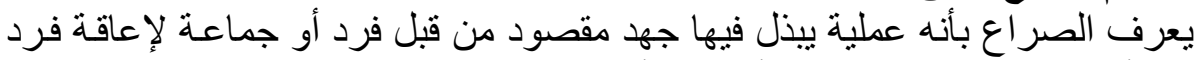

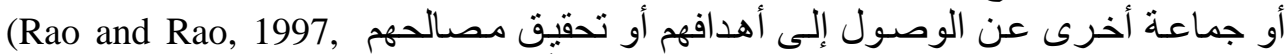

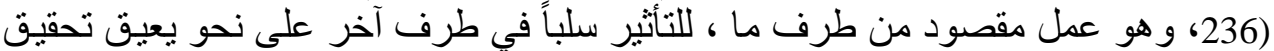

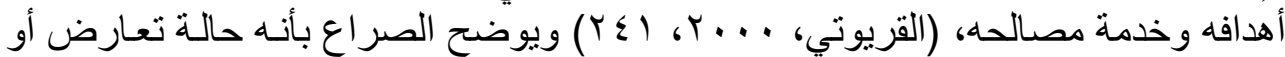

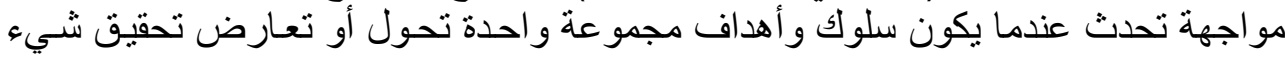




\section{الجميل [ب [1]}

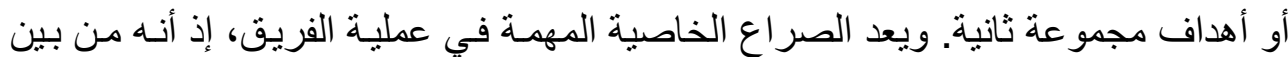

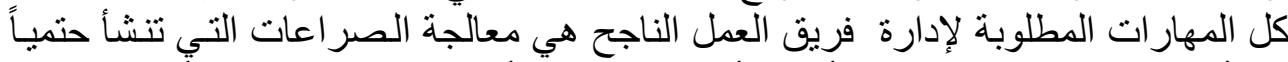

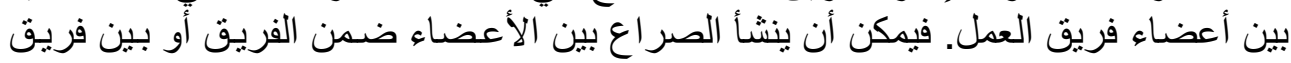

ثُانياً. أسباب صراع فريث العمل

من أسباب الصراع اعزئ هو التفاعل العدائي الذي يحاول فيه كل طرف إيقاف اهتمامـات

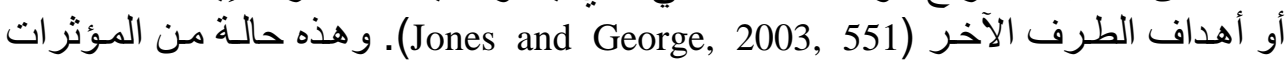

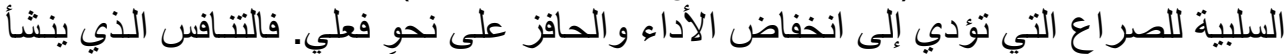

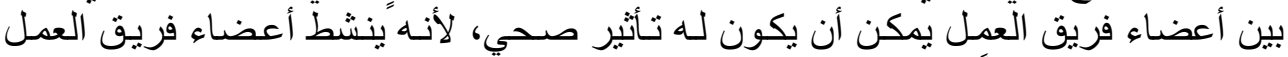

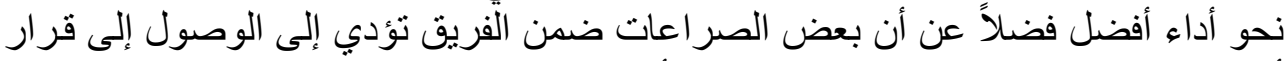

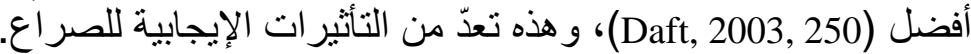

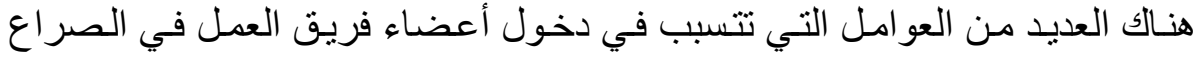

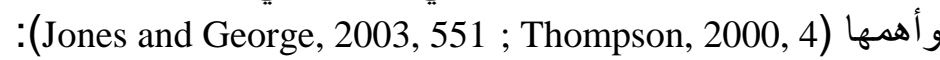

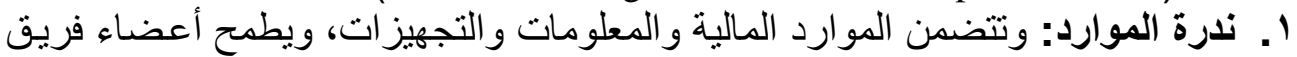

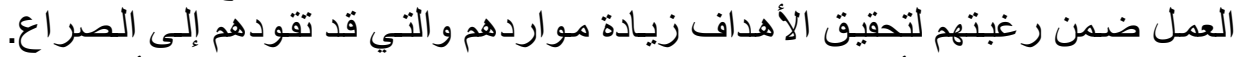

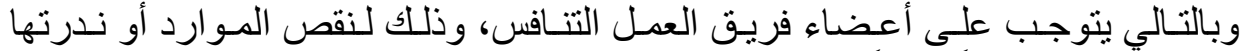

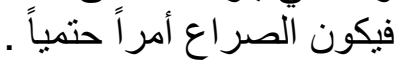

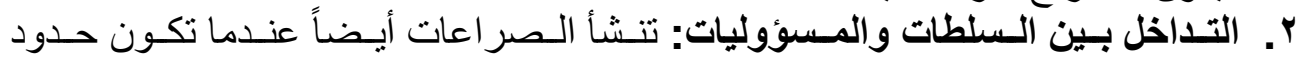

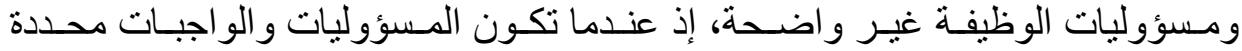

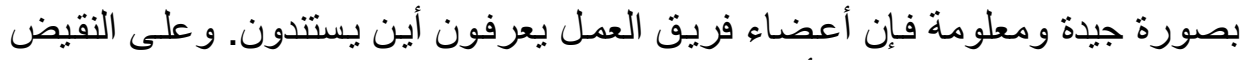

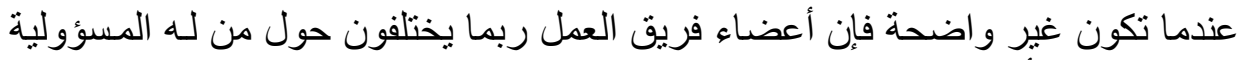

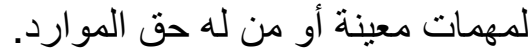

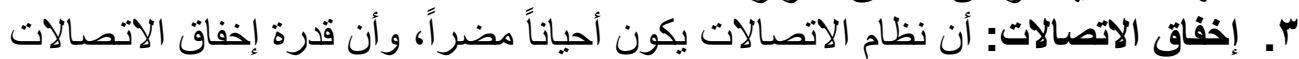

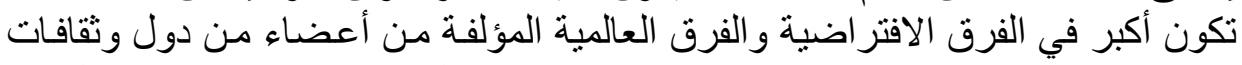

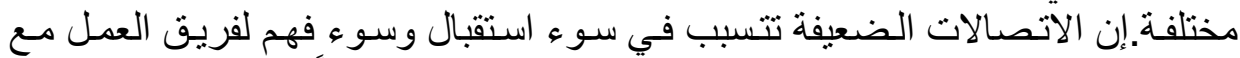

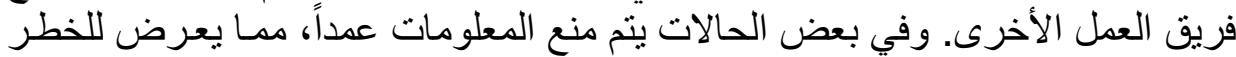

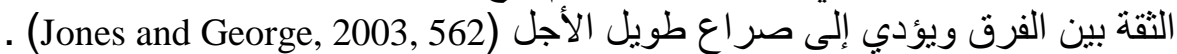

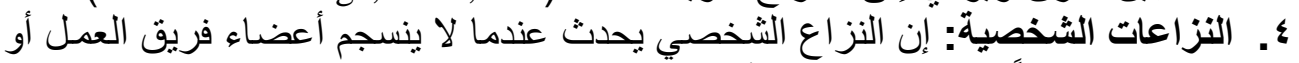

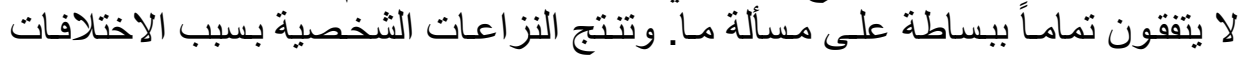

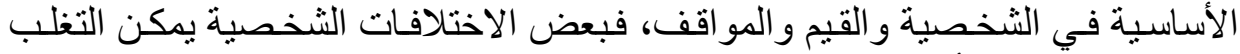

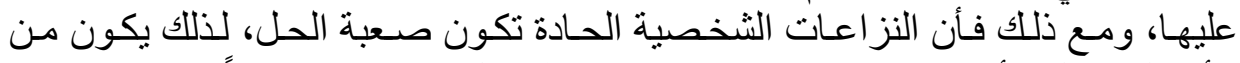

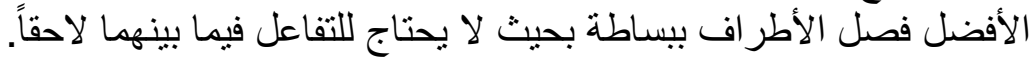

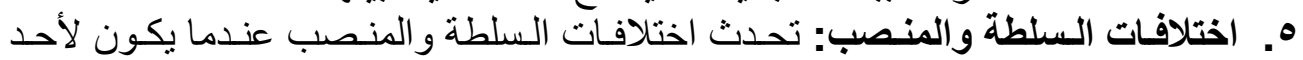

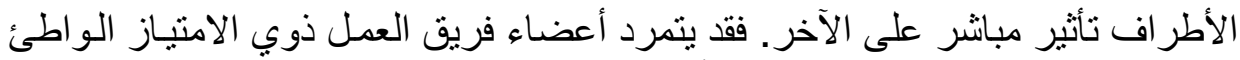

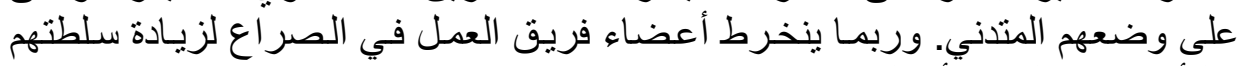

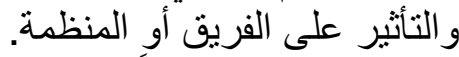

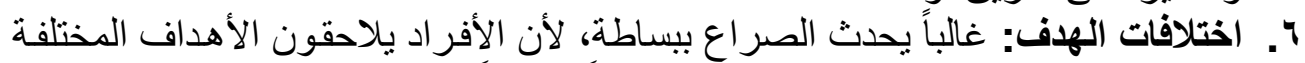

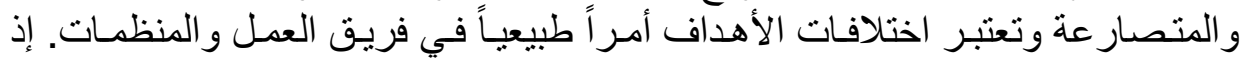


تضع أهداف فريق العمل في صراع مع أهداف فريق عمل آخر. أو ربمـا تضع أهداف

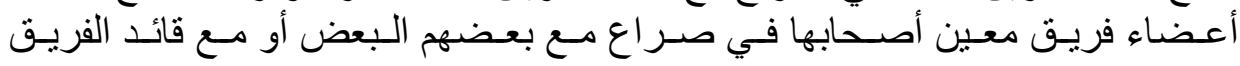

.(Thompson, 2000, 40)

\section{تُالثاً أساليب معالجة صراع فريق العمل}

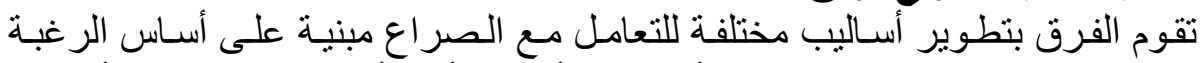

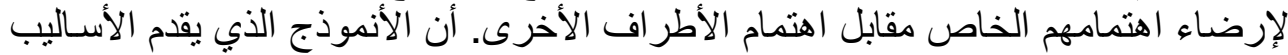

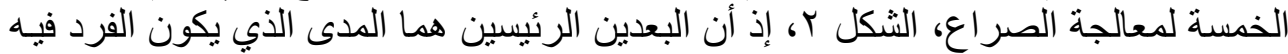

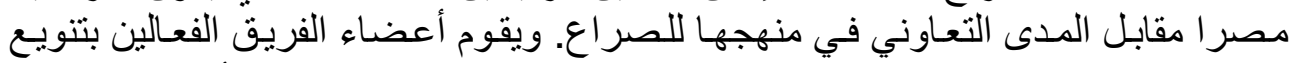

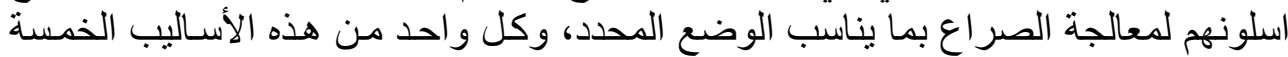
يناسب حالات محددة، وكالآتي (Daft, 2003, 634):

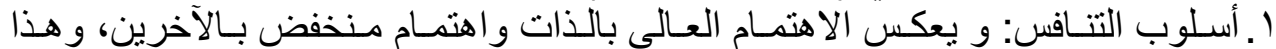

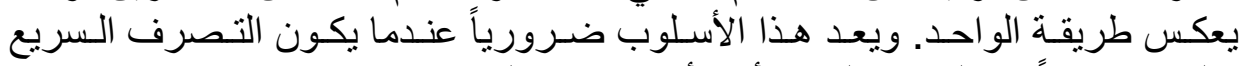

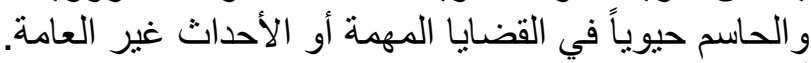

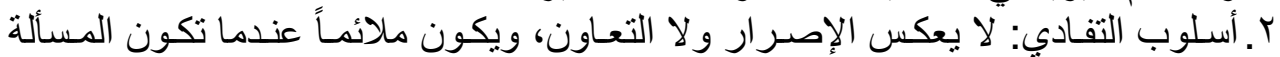

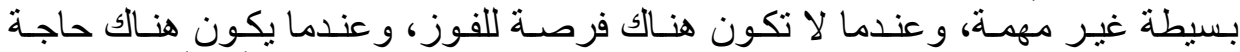

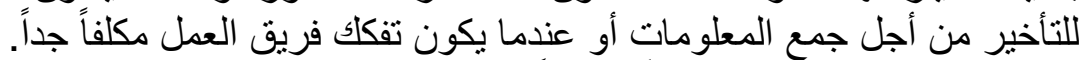

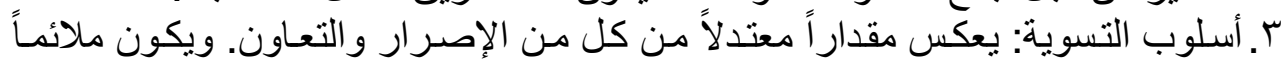

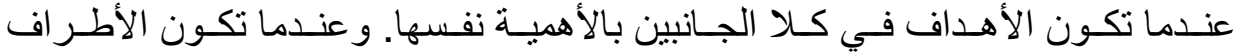

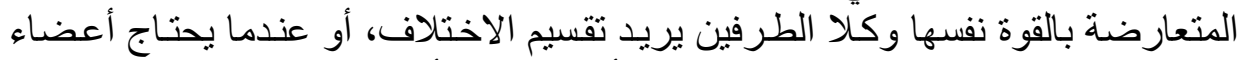

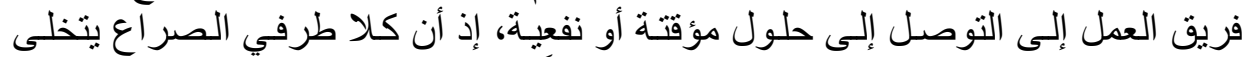

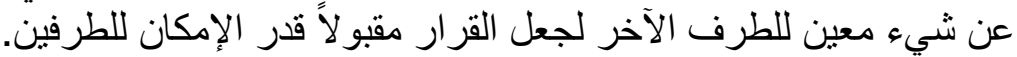

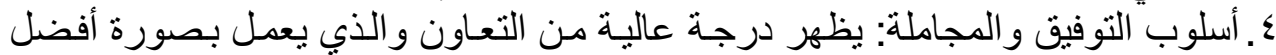

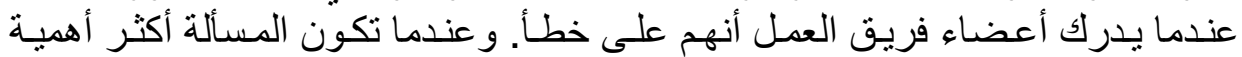

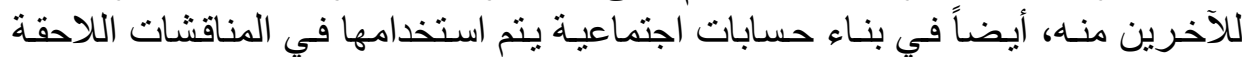

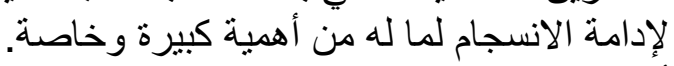

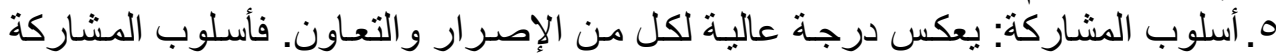

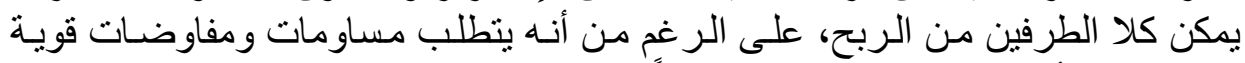

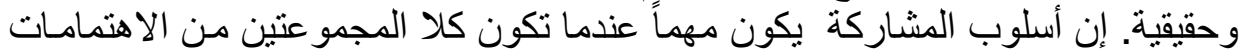

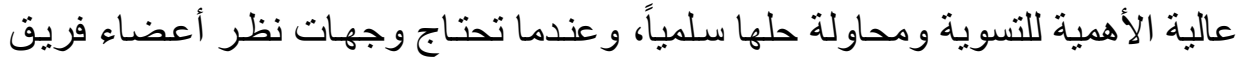

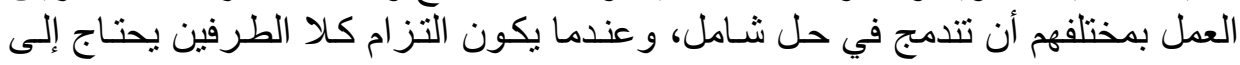

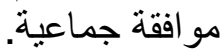
أن الأسـاليب المختلفة لمعالجة صر اع فريق العمل يمكن استخدامها عندما لا يتفق

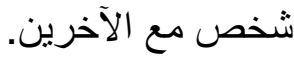




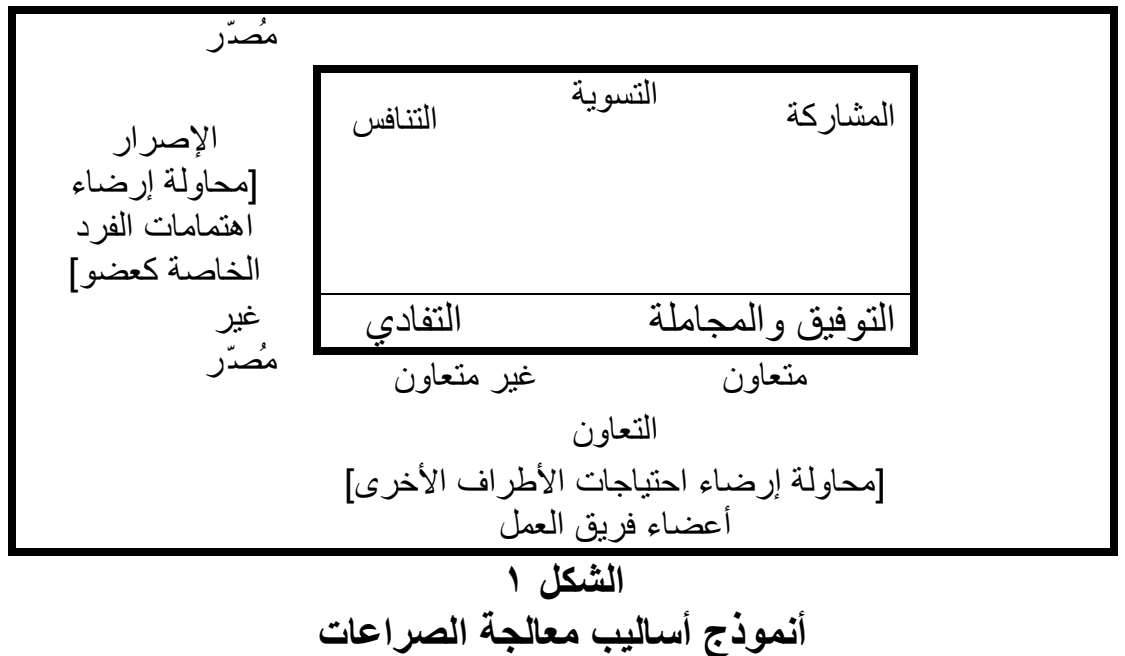

Source: Daft, Richard L. (2003). Management (Australia: Thomson, South Western), 633.

\section{الجانب المياني \\ أولاً - وصف بعدي البحث وتشخيصهما

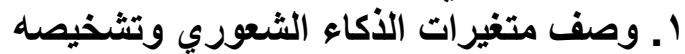

تشير معطيات الجدول ب إلى الأوساط الحسابية والانحر افات المعات المعيارية الخاصة بيعد

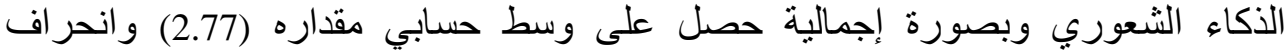
معياري بمقدار (0.48) وإجابات عينة البحث تجاه أبعاد الذكاء الشعورية الثابة تبين (84.7\%)

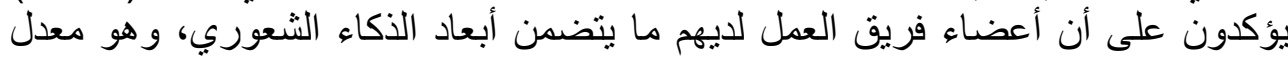

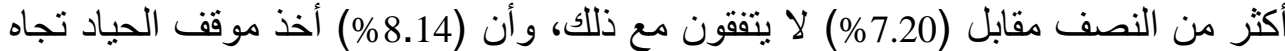

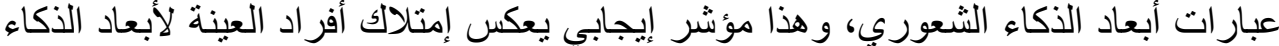

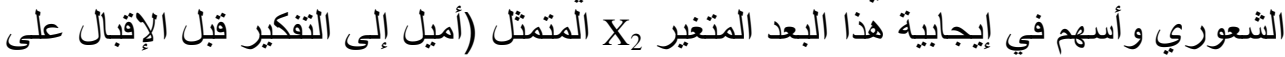

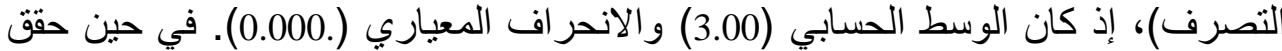
المتغير (X) الذي يتضمن العبارة (أميل إلى توظيف مشاعري المختلفة تجاه الأمور المطروحة) أدنى وسط حسابي مقداره (2.43) بانحر اف معياري (0.82) وجاءت الفي المتغيرات الباقية ما بين قيم المتغيرين السابقين.

\begin{tabular}{|c|c|c|c|c|c|c|c|c|}
\hline \multicolumn{9}{|c|}{ وصف متغيرات الأكاء الشعوري وتشخيصه } \\
\hline \multirow{3}{*}{ المعياري } & \multirow{3}{*}{ الحسابي } & \multirow{2}{*}{\multicolumn{2}{|c|}{$\frac{1}{1}$}} & \multirow{2}{*}{\multicolumn{2}{|c|}{ محايد }} & \multirow{2}{*}{\multicolumn{2}{|c|}{$\begin{array}{c}\text { أتفق } \\
\end{array}$}} & \multirow{3}{*}{ المتغيرات } \\
\hline & & & & & & & & \\
\hline & & $\%$ & ت & $\%$ & $ت$ & $\%$ & $ت$ & \\
\hline 0.849 & 2.50 & 22.7 & 10 & 4.5 & 2 & 72.7 & 32 & $X_{1}$ \\
\hline 0.000 & 3.00 & - & - & - & - & 100 & 44 & $X_{2}$ \\
\hline 0.509 & 2.80 & 4.5 & 2 & 11.4 & 5 & 84.1 & 37 & $X_{3}$ \\
\hline 0.522 & 2.77 & 4.5 & 2 & 13.6 & 6 & 81.8 & 36 & $\mathrm{X}_{4}$ \\
\hline 0.334 & 2.93 & 2.3 & 1 & 2.3 & 1 & 95.5 & 42 & $\mathrm{X}_{5}$ \\
\hline
\end{tabular}




\begin{tabular}{|c|c|c|c|c|c|c|c|c|}
\hline \multirow{3}{*}{ الأنحراف } & \multirow{3}{*}{ الحسابي الوسط } & \multirow{2}{*}{\multicolumn{2}{|c|}{ 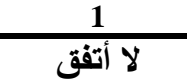 }} & \multirow{2}{*}{\multicolumn{2}{|c|}{$\frac{2}{2}$}} & \multirow{2}{*}{\multicolumn{2}{|c|}{$\frac{3}{\text { أتفقق }}$}} & \multirow{3}{*}{ المتغيرات } \\
\hline & & & & & & & & \\
\hline & & $\%$ & $ت$ & $\%$ & ت & $\%$ & $ت$ & \\
\hline 0.818 & 2.43 & 20.5 & 9 & 15.9 & 7 & 63.6 & 28 & $X_{6}$ \\
\hline 0.302 & 2.95 & 2.3 & 1 & - & - & 97.7 & 43 & $\overline{X_{7}}$ \\
\hline 0.409 & 2.86 & 2.3 & 1 & 9.1 & 4 & 88.6 & 39 & $\mathrm{X}_{8}$ \\
\hline 0.334 & 2.93 & 2.3 & 1 & 2.3 & 1 & 95.5 & 42 & $X_{9}$ \\
\hline 0.387 & 2.89 & 2.3 & 1 & 6.8 & 3 & 90.9 & 40 & $\mathrm{X}_{10}$ \\
\hline 0.820 & 2.45 & 20.5 & 9 & 13.6 & 6 & 65.9 & 29 & $\mathrm{X}_{11}$ \\
\hline 0.476 & 2.77 & 2.3 & 1 & 18.2 & 8 & 79.5 & 35 & $\mathrm{X}_{12}$ \\
\hline 0.478 & 2.77 & 7.20 & & 8.14 & & 84.65 & & المعدل \\
\hline
\end{tabular}

r. وصف متغيرات إدارة صراع فريق العمل وتثخيصها:

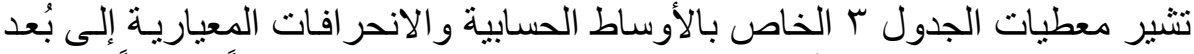

أساليب حل صر اع فريق العمل بأن هذا المتغير بصورة إجمالية حقق وسطاً حسابياً بمقدارها

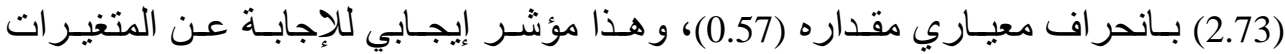

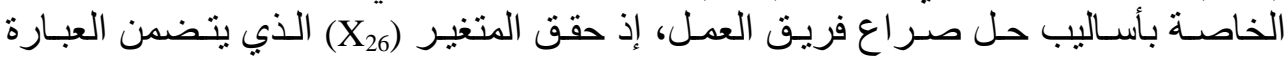

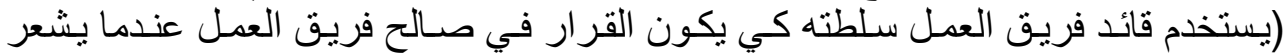

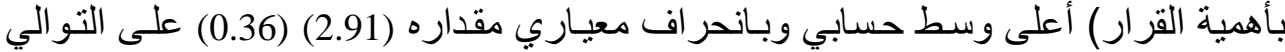
وقد أسهم في إيجابية هذا البعد، في حين حقق المتغير (X $)$ المتمثنل بالعبارة الآتيـة (يعمل

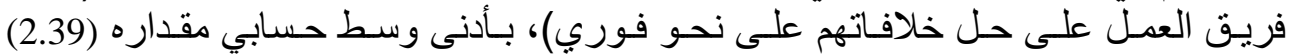
بانحر اف معياري مقداره (0.868) وجاءت المتغير ات الباقية ما بين قيم المتغيرين السابقين.

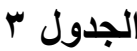

وصف متغيرات إدارة صراع فريق العمل وتثخيصها

\begin{tabular}{|c|c|c|c|c|c|c|c|c|}
\hline \multirow{3}{*}{ الانحراف } & \multirow{3}{*}{ الحسابي } & \multirow{2}{*}{\multicolumn{2}{|c|}{$\frac{1}{\text { لأتفق }}$}} & \multirow{2}{*}{\multicolumn{2}{|c|}{$\frac{2}{2}$}} & \multirow{2}{*}{\multicolumn{2}{|c|}{ أتفق }} & \multirow{3}{*}{ المتغيرات } \\
\hline & & & & & & & & \\
\hline & & $\%$ & ت & $\%$ & $ت$ & $\%$ & $ت$ & \\
\hline 0.565 & 2.77 & 6.8 & 3 & 9.1 & 4 & 84.1 & 37 & $X_{13}$ \\
\hline 0.451 & 2.73 & - & - & 27.3 & 12 & 72.7 & 32 & $\mathrm{X}_{14}$ \\
\hline 0.722 & 2.61 & 13.6 & 6 & 11.4 & 5 & 75.0 & 33 & $X_{15}$ \\
\hline 0.792 & 2.48 & 18.2 & 8 & 15.9 & 7 & 65.9 & 29 & $X_{16}$ \\
\hline 0.522 & 2.77 & 4.5 & 2 & 13.6 & 6 & 81.8 & 36 & $X_{17}$ \\
\hline 0.495 & 2.82 & 4.5 & 2 & 9.1 & 4 & 86.4 & 38 & $\mathrm{X}_{18}$ \\
\hline 0.868 & 2.39 & 25.0 & 11 & 11.4 & 5 & 63.6 & 28 & $X_{19}$ \\
\hline 0.409 & 2.86 & 2.3 & 1 & 9.1 & 4 & 88.6 & 39 & $\overline{X_{20}}$ \\
\hline 0.509 & 2.80 & 4.5 & 2 & 11.4 & 5 & 84.1 & 37 & $X_{21}$ \\
\hline 0.509 & 2.80 & 4.5 & 2 & 11.4 & 5 & 84.1 & 37 & $X_{22}$ \\
\hline 0.818 & 2.57 & 20.5 & 9 & 2.3 & 1 & 77.3 & 34 & $X_{23}$ \\
\hline 0.495 & 2.82 & 4.5 & 2 & 9.1 & 4 & 86.4 & 38 & $X_{24}$ \\
\hline 0.479 & 2.84 & 4.5 & 2 & 6.8 & 3 & 88.66 & 39 & $X_{25}$ \\
\hline 0.362 & 2.91 & 2.3 & 1 & 4.5 & 2 & 93.2 & 41 & $X_{26}$ \\
\hline 0.571 & 2.73 & & & & & & & المعدل \\
\hline
\end{tabular}


ثانياً اختبار فرضيات البحث

يختص هذا المحور بالتعرف على البث طبيعة وقوة علاقات الارتباط و التأثير بين متغيري

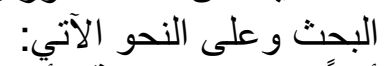

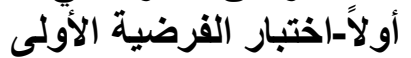

اختصت هذه الفرضية بالعلاقة بين متغيري البحث، ويوضح الجدول ؛ نتائج تحليل الارتباط.

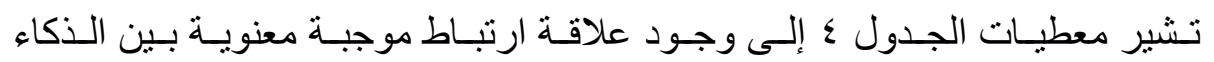

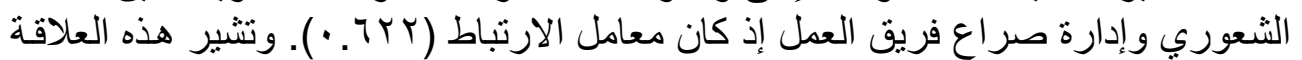

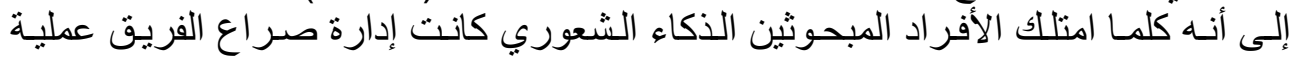

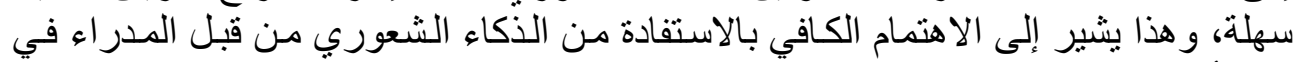

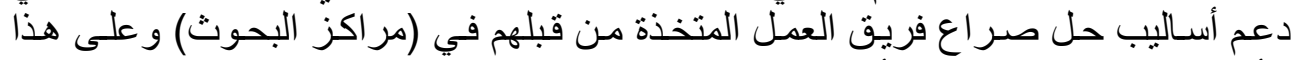

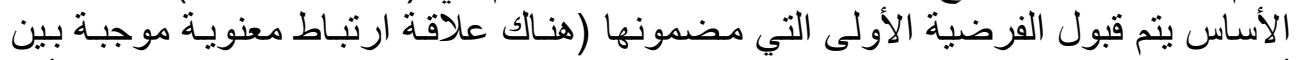

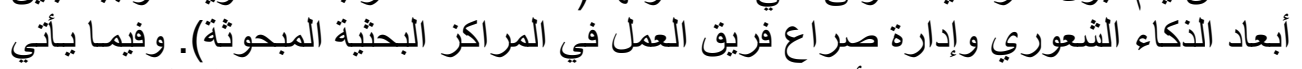

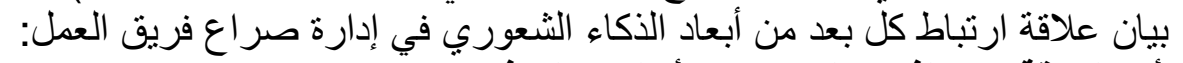

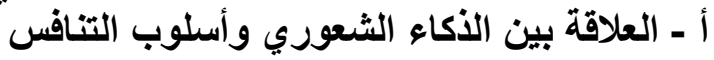

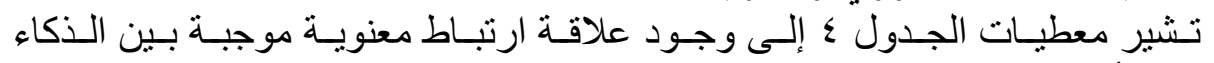

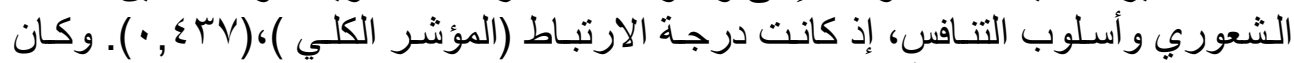

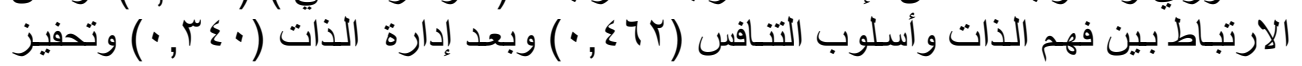

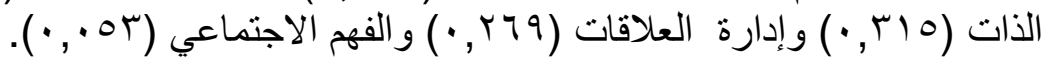

ب- العلاقة بين الأكاء الشعوري وأسلوب التفادي

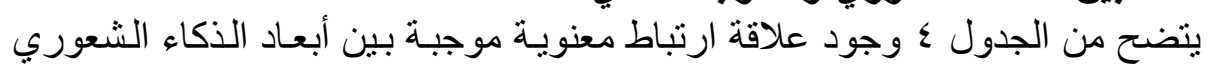

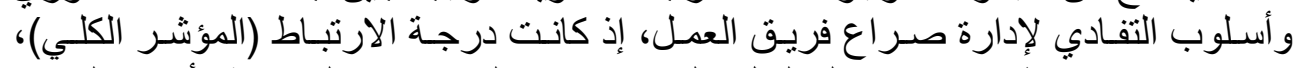

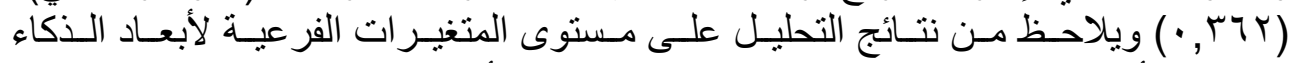

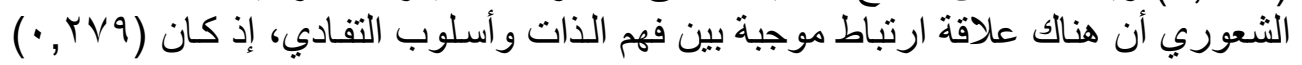

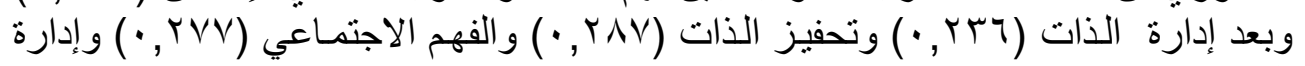

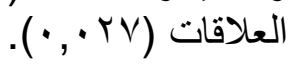

ج- العلاقة بين الأكاء الشعوري وأسلوب التسوية في إدارة صراع فريق العاب العمل

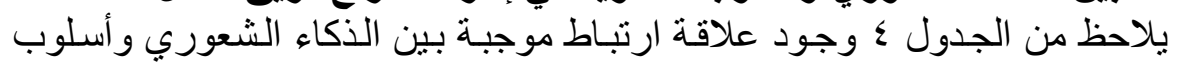

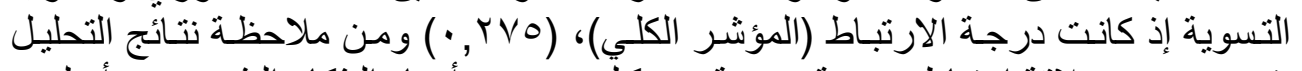

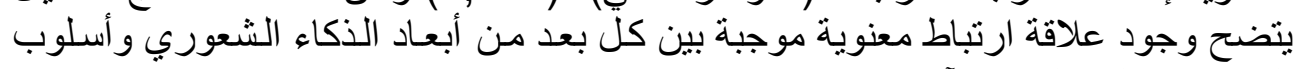

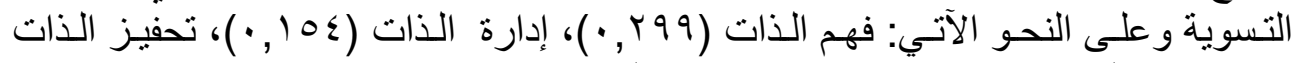

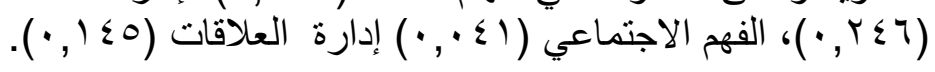

ت- العلاقة بين الأكاء الشعوري وأسلوب التوفيق والمجاملة

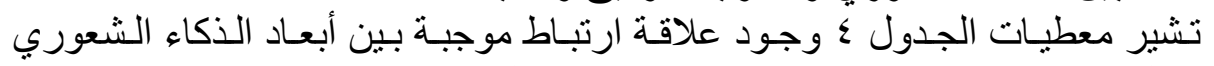

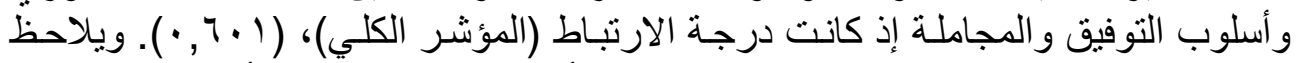

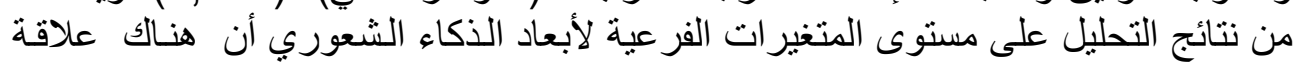




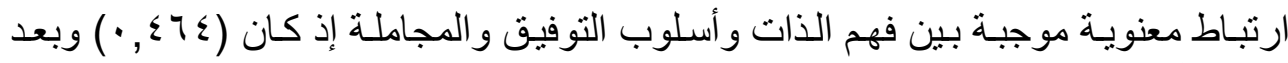

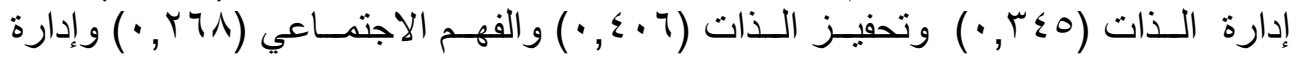

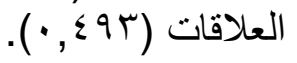

حـ العلاقة بين الأكاء الثعوري وأسلوب المشاركة إنابة

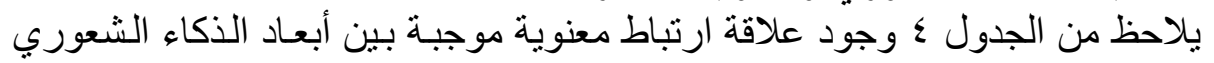

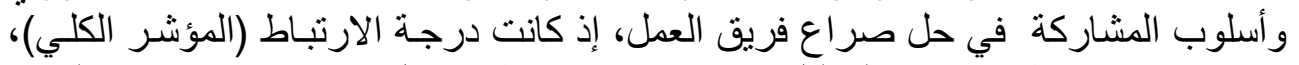

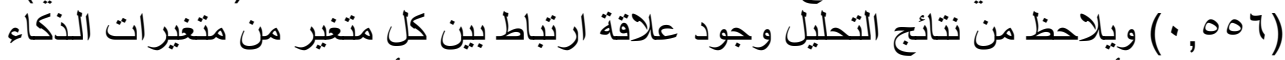

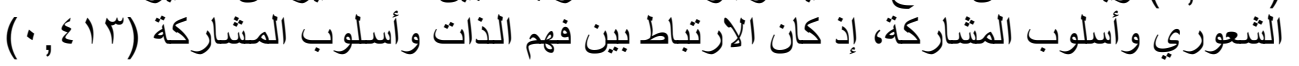

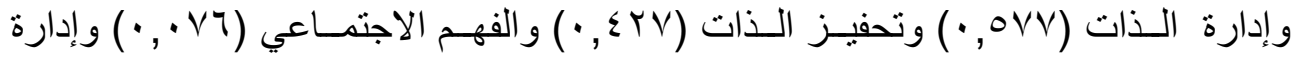

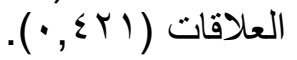

\begin{tabular}{|c|c|c|c|c|c|c|}
\hline \multicolumn{7}{|c|}{ العلاقة بين الأكاء الشعوري وإدارة صراع فريق العمل على المستوى الكلي للمتغيرات } \\
\hline المؤشي & العلاقات & الاجتماعي & الذاتيز & الألات & الذات & إدارة صــاع الشعوريـق العمل \\
\hline${ }^{* *} \cdot, \varepsilon r V$ & $\cdot, r 79$ &., or & ${ }^{*} \cdot, r_{10}$ & $*, r \leq$. & ${ }^{* *} \cdot, \leq 7 T$ & أسلوب التنافس \\
\hline${ }^{*} \cdot,{ }^{*}, r$ & $\cdot, \cdot T V$ & $\cdot, Y Y Y$ & $\cdot$, YAV & •, YYT & $\cdot, r \vee q$ & أسلوب التفادي \\
\hline$\cdot$ r YVO & $\cdot, 1 \leq 0$ & $\cdot, \cdot \sum 1$ & $\cdot, Y \leq T$ & $\cdot, 10 \xi$ & ${ }^{*} \cdot, 199$ & أسلوب التسوية \\
\hline$\star \star *, 7,1$ & ${ }^{* *} \cdot, \leqslant 9 T$ & $\cdot, r \neg \wedge$ & ${ }^{* *} \cdot, \varepsilon \cdot 7$ & ${ }^{*}, r, r \leq 0$ & ${ }^{* *} \cdot, \leq 7 \leq$ & أسلوب التوفيق والمجاملة \\
\hline$\star \star, 007$ & ${ }^{\star \star} \cdot, \varepsilon \vee \wedge$ & $\cdot, \cdot \times 4$ & ${ }^{* \star} \cdot, \varepsilon Y V$ & ${ }^{* *} \cdot$, OVV & ${ }^{* *} \cdot, \varepsilon \mid \Gamma$ & أسلوب المشاركة \\
\hline${ }^{*} \cdot, T Y Y$ & ${ }^{* *} \cdot,\{r)$ & $\cdot, 177$ & $\star \star *, \leqslant 79$ & ${ }^{* *} \cdot, \varepsilon \wedge \gamma$ & $* *, 047$ & المؤشر الكلي \\
\hline
\end{tabular}

المصدر : من إعداد الباحثة بالاعتماد على نتائج الحاسبة الالكثرونية

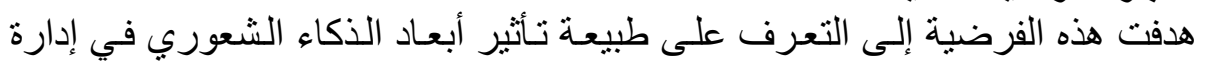
صراع فريق العمل ويشير الجدول ه إلى اختبار هذه الفرضية.

\section{- الجدول}

نتائج تحليل الاتحدار للأكاء الشعوري في إدارة صراع فريق الثرئ العمل

\begin{tabular}{|c|c|c|c|c|c|}
\hline \multicolumn{5}{|c|}{ الأكاء الثعوري } & 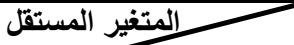 \\
\hline & & P & $\mathrm{M}$ & 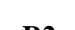 & \multirow{3}{*}{ إدارة صراع فريق العمل } \\
\hline الجدولية & المحسوبة & Во & B1 & R2 & \\
\hline • & $\cdot, \wedge \vee$. & $\cdot, \varepsilon)$. & $r q, 1 \leqslant r^{* *}$ & $v, r$ & \\
\hline
\end{tabular}

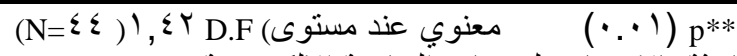

المصدر : من إعداد الباحثة بالاعتماد على نتائج ألحاسبة الالكترونية 


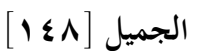

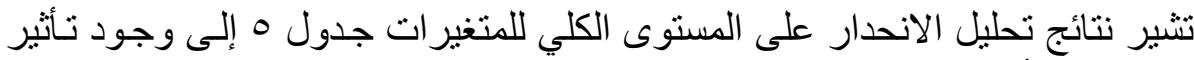

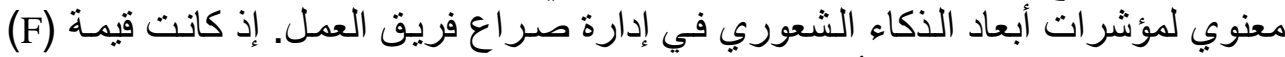

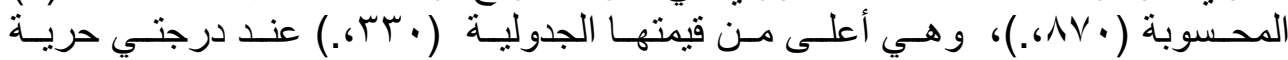

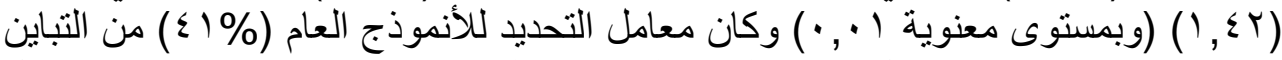
في إدارة صراع فريق العمل يفسره الذكاء الثعوري للمبحوثين في المر اكز البحثية، وتمثنل

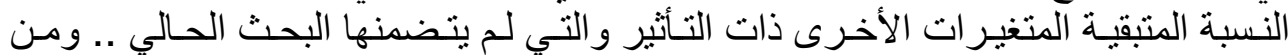

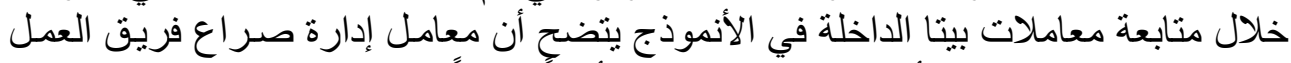

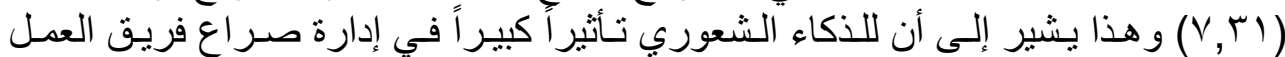

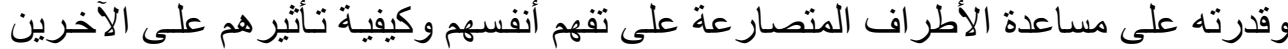

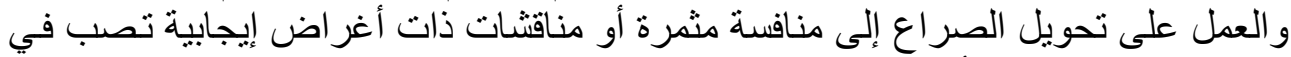

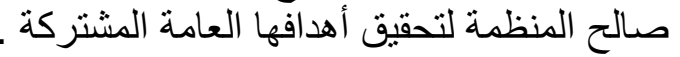

\section{الجدول}

نتائج تحليل الاتحدار لأبعاد الأكاء الشعوري في إدارة صراع فريق العمل

\begin{tabular}{|c|c|c|c|c|c|c|c|c|}
\hline المحسوبة & $\mathbf{R 2}$ & العلاقات & الاجتماعي & تحفيز & ألأدات & فهم & Bo & \\
\hline$r, v \varepsilon$ & 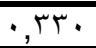 & $-\cdot, Y \cdots$ & $-\cdot, Y \backslash 1$ & $\cdot, Y Y T$ & $V 17$, & $\cdot, r q \mu$ & $\cdot, 119$ & أسلوب التنافس \\
\hline$r, r \cdot r$ & •, Yro & $-\cdot, r q r$ & • & $\cdot, r \cdot \varepsilon$ & ס & $\cdot, r 10$ & $1, r \cdot V$ & أسلوب التفادي \\
\hline 1, 1, & $\cdot, 1 \leq$. & $-\cdot, 1 \leq 0$ & $-\cdot, 90$ & $\cdot, Y 7 \Lambda$ & $\cdot, I T r$ & $\cdot, 119$ & $1,10$. & أسلوب التسوية \\
\hline$\varepsilon, 9 \wedge r$ & $\cdot, r 97$ & $\cdot, r)$ & $\cdot, 1 \leq V$ & $\cdot, 17 \varepsilon$ & $\cdot, \cdot Y I$ & $\cdot, 1 \wedge \varepsilon$ & $\cdot, 041$ & أسلوب التوفيق و المجاملة \\
\hline V,YYY & $\cdot, \leqslant \wedge \vee$ & $\cdot, 1 \cdots$ & $-\cdot, Y \vee \wedge$ & $\cdot, 1 \leqslant V$ & $1, \leqslant 7 \pi$ & $\cdot, 101$ & $-Y, \leqslant r_{0}$ & أسلوب المشاركة \\
\hline \multicolumn{4}{|c|}{$\mathrm{P}<\cdot, \cdot 1$} & \multicolumn{3}{|c|}{ D.F $(0, r \wedge)$} & & $\begin{array}{l}=\varepsilon \\
\text { ن إعد }\end{array}$ \\
\hline
\end{tabular}

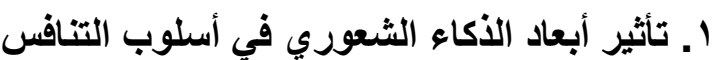

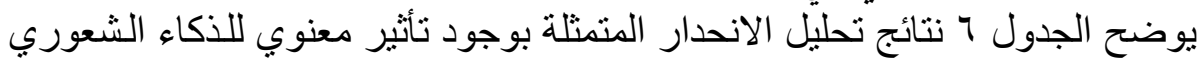

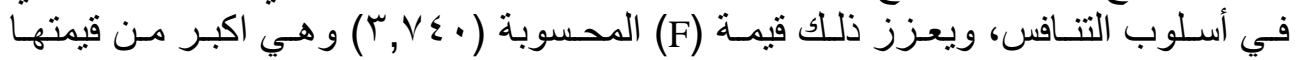

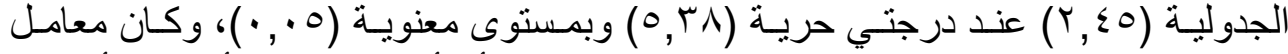

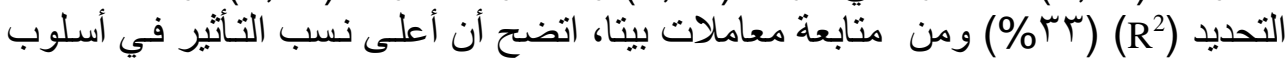

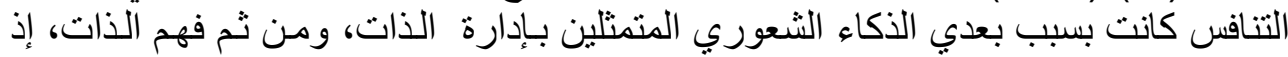

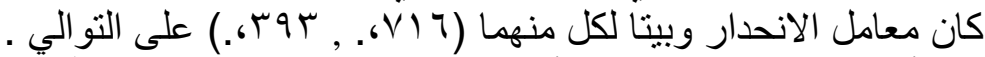

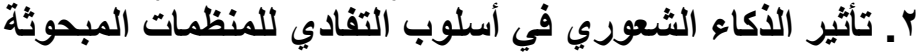

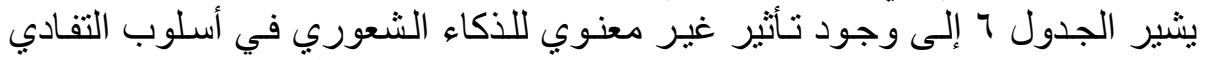

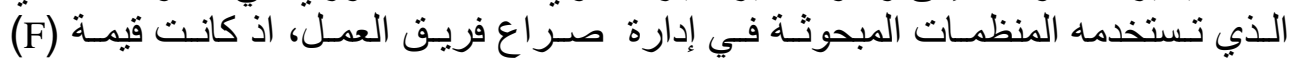

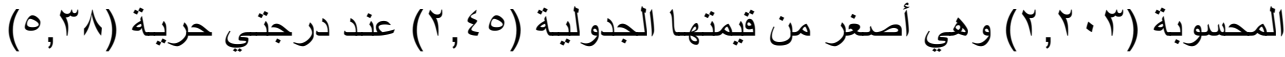

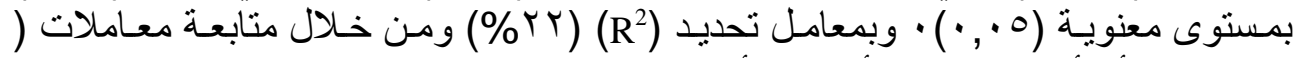

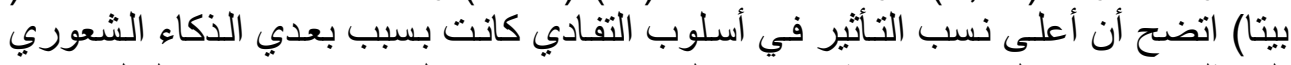

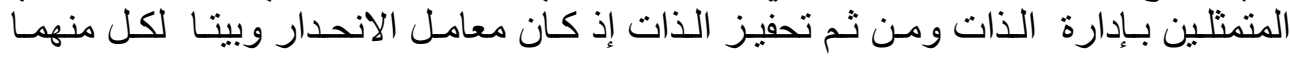

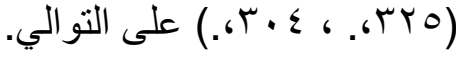


r. تأثير الذكاء الثعوري في أسلوب التسوية للمنظمات المبحوثة

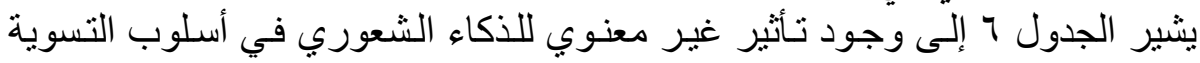

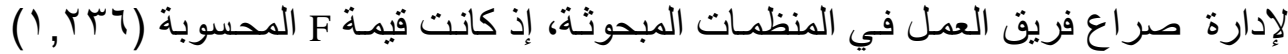

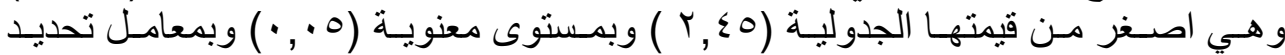

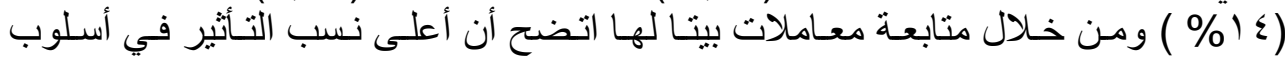

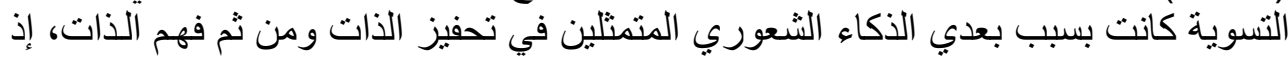

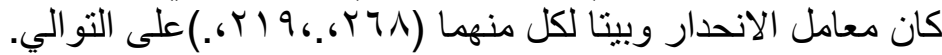

؛ـ تأثير الذكاء الثعوري في أسلوب التوفيق والمجاملة

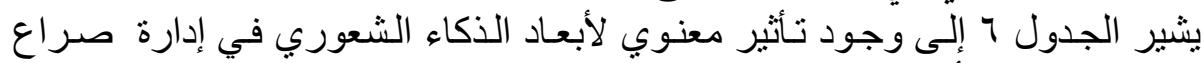

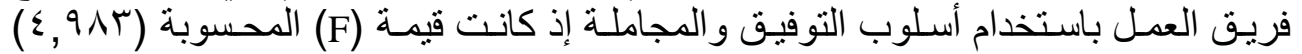

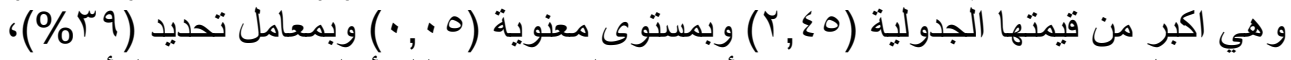

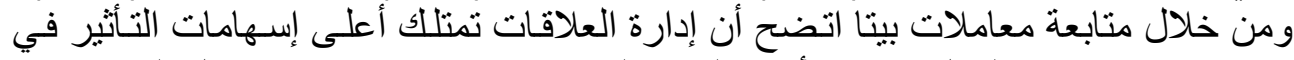

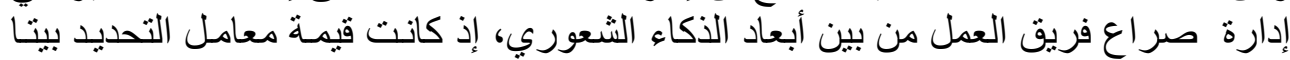

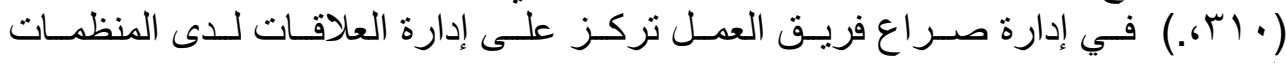

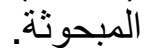

هـ تأثير الذكاء الثعوري في أسلوب المشاركة

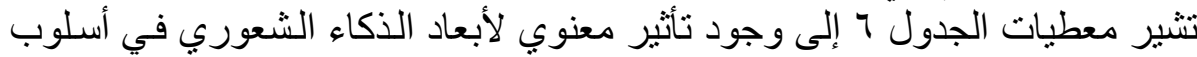

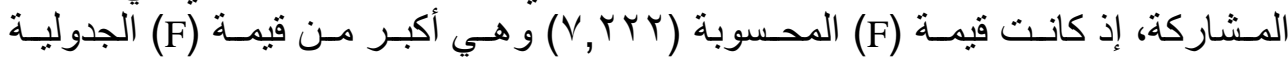

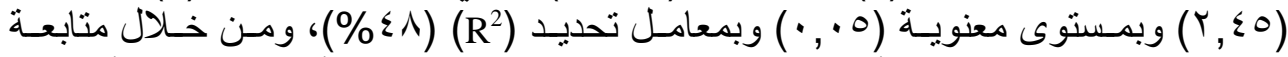

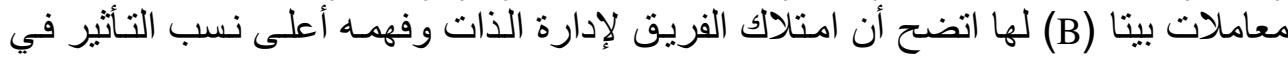

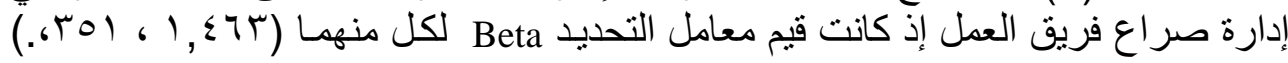

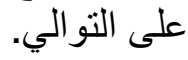

الاستتتاجات والمقترحات أولاً. الاستنتاجات المتاجترات

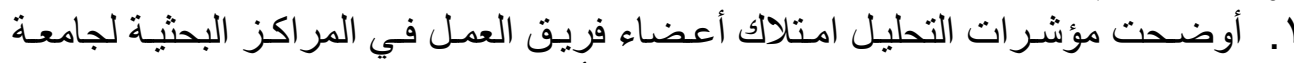

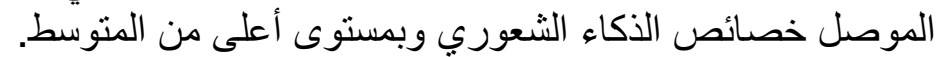

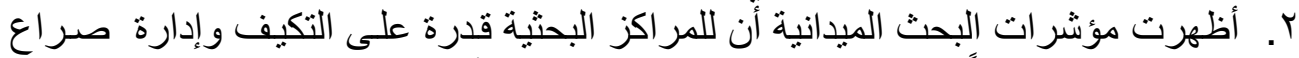

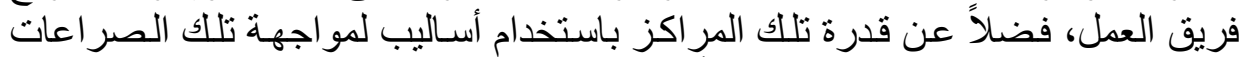
وكان بمستوى أعلى من المتوسط أيضاً.

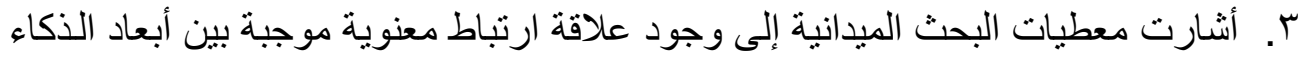

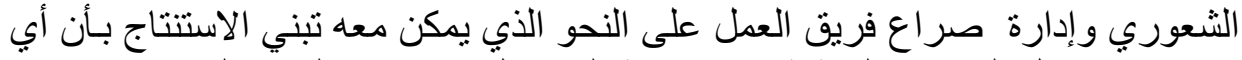

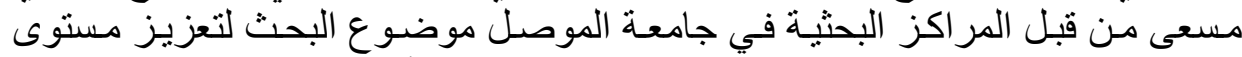

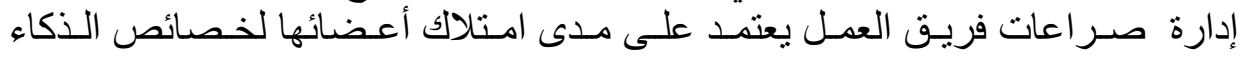

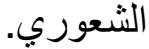

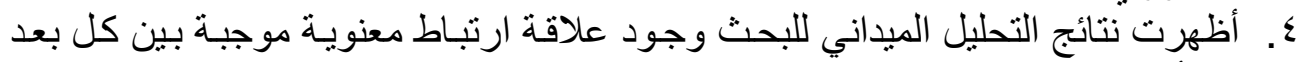

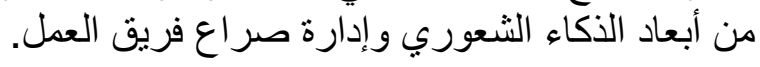




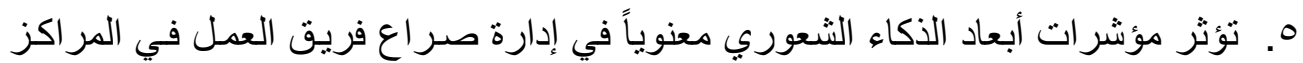

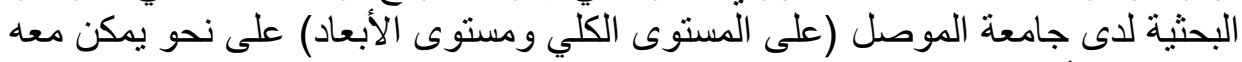

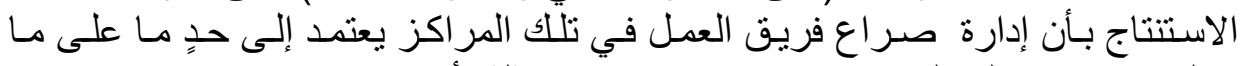

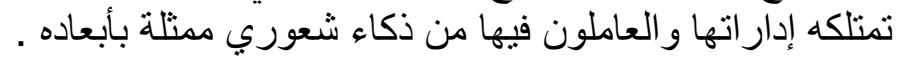

\section{ثانياً. المقترحات}

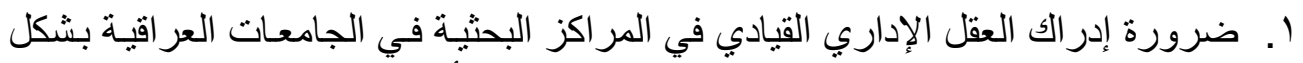

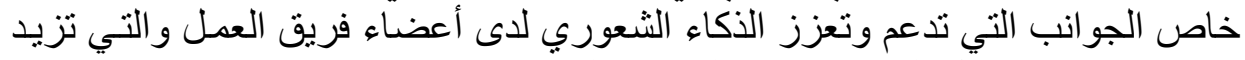

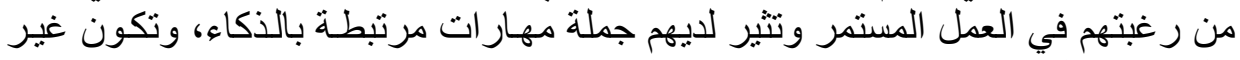

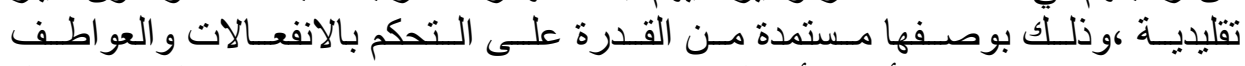

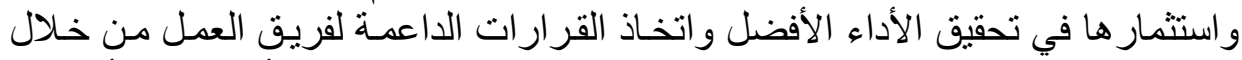

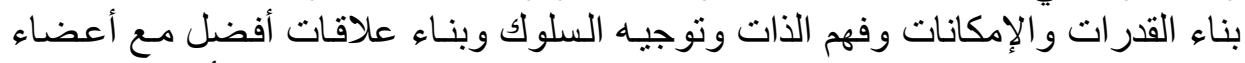

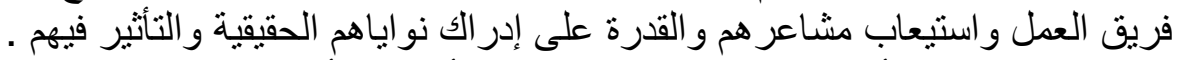

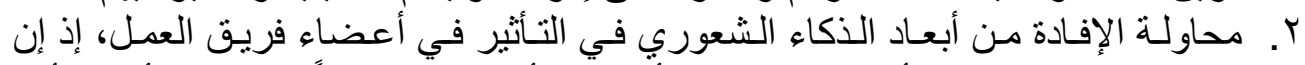

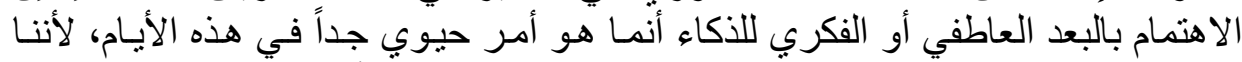

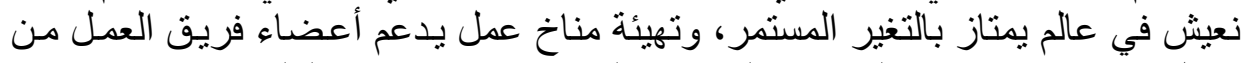

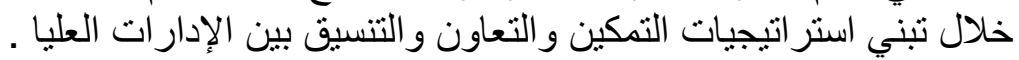

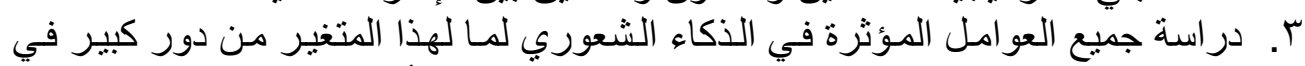

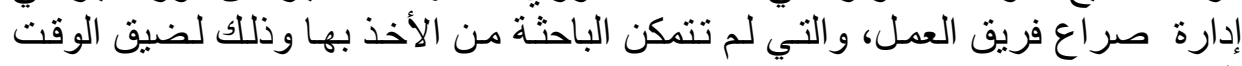
المتاح.

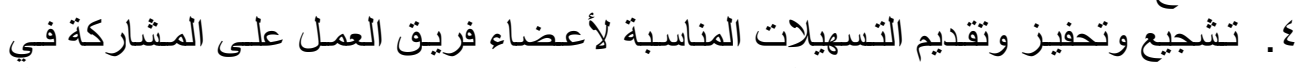

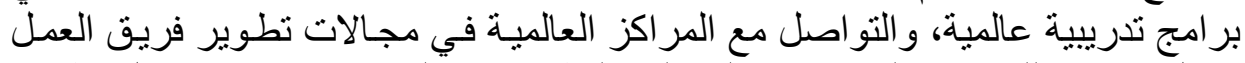

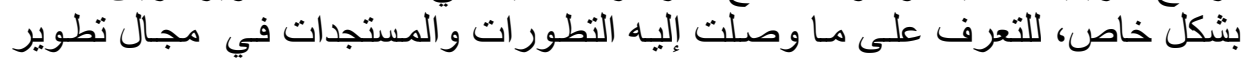

$$
\text { وتتمية الموارد البشرية. }
$$

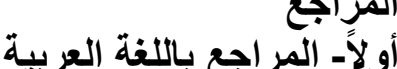

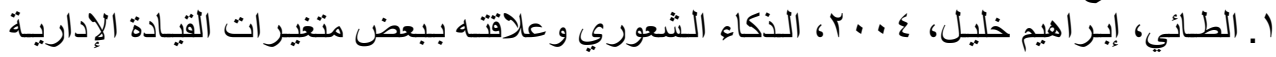

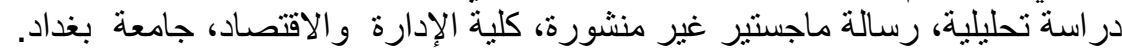

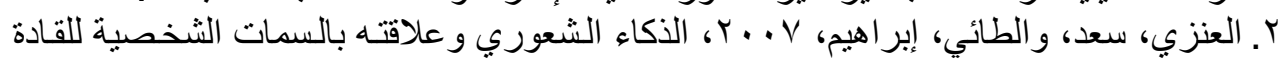

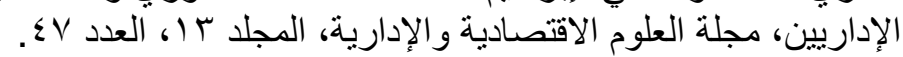

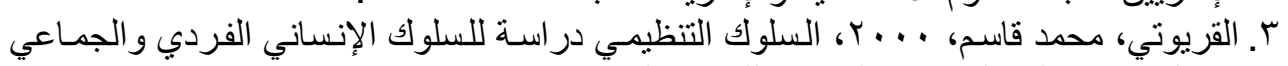

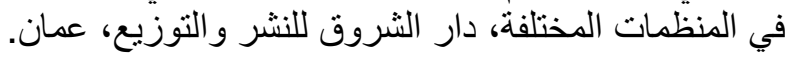

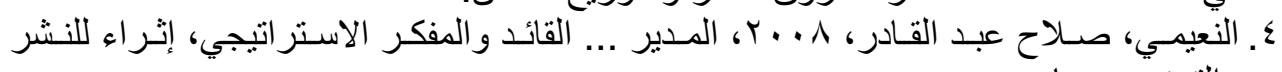

\section{ثاتياً- المراجع باللغة الأجنبية}

1. Mayer,J.D.and Salovey, p . 1999 Emotional Intelligence Meets Traditional Standards for an intelligence.vol .27, No .12:267-298.

2. Festa, R.M. 2001 Impacting performance through emotional intelligence. Paper presented at conference mortgage bankers association of America, 20 June. 
3. Daft, Richard L. 2003. Management. Australia: Thomson, South Western.

4. Daft,Richard L.andNoe, Raymond.A 2001, Organizational Behavior,Harcourt Inc.,U.S.A

5. Dulewicz,S.V. and Higgs, M.J., 2000. Emotional intelligence: A review and evaluation study, Journal of Management Psychology, vol. 72, No.9

6. Goleman, D. 1998 Working with emotional intelligence, New York: Bantam Books.

7. Jones, Gareth R. and George Jennifer M. 2003. Management McGraw Hill, Irwin U.S.A.

8. Rao,M.and Rao, v. 1997 Organizational Behavior Delhi,kinark puplishers, USA.

9. Schermerhosn, John, R. 2002. Management,: John Wiley and Sons Inc‘ New York

10. Thompson, Leigh, 2000, Making the team,: Prentice Hall ‘ New Jersey.

- Recker, Nancy K., (2001), "Emotional Intelligence what is it," www.hee.ohio.edu/famlife.

- Rotheman, S. (2002) Personality preferences and emotional intelligence implications for small and medium sized enterprices. Puknet puk www.bpksr. 